\title{
Multiplexity and Strategic Alliances: The Relational Embeddedness of Coalitions in Social Movement Organisational Fields ${ }^{*} \dagger$
}

\section{ACCEPTED AUTHOR MANUSCRIPT}

To appear in Social Networks

Please consult final published version before citing.

February $23^{\text {st }} 2015$

\author{
Cohen R. Simpson \\ Doctoral Candidate \\ Department of Methodology \\ The London School of Economics \& Political Science \\ c.r.simpson@lse.ac.uk
}

NOTICE: This is the author's version of a work that was accepted for publication in Social Networks. Changes resulting from the publishing process such as editing, corrections, structural formatting, and other aspects of quality control may not be reflected in this document.

\footnotetext{
${ }^{*}$ Coloured figures are used in this work.

${ }^{\dagger}$ In crafting this work I am grateful for the guidance of Garry Robbins, Johan Koskinen, Sarah Soule, Ioanna Gouseti and the three anonymous reviewers. Additionally I wish to thank the members of the Network Modelling group at Nuffield College, The University of Oxford with whom I presented to and discussed this work a number of times during its maturation.
} 
ABSTRACT: While scholars have embraced the notion of social movements as networks, there has been little empirical exploration of the dynamics of alliance formation within these multilayered systems. Here I explore the role of overlapping relations in alliance formation amongst a group of 55 health-related professional social movement organisations (SMOs) mobilised against austerity. Using cross-sectional bivariate exponential random graph models, Ifind dependencies between digital proxies for alliance, shared allies, information exchange, positive nomination and offline co-lobbying activity at the dyadic, degree and triadic levels. Cross-network associations indicate that multiplexity plays a non-trivial role in the formation of alliances and, more generally, social movement organisational fields, necessitating increased attention from movement scholars.

\section{HIGHLIGHTS}

*Alliance is heavily embedded suggesting cost minimisation is a dyadic aspect of its formation *SMOs may pool allies and entrained resources without establishing alliances with others

*Alliance is structurally embedded in multiplex triadic configurations of expressive ties

*Uncertainty reduction vis-à-vis identity governs alliance formation in the presence of positive nomination

*Micro-macro integration of organisational fields is a function of multilevel and multiplex dynamics

KEYWORDS: Multiplexity; Social Movement Organisations; Alliance; Competition; Exponential Random Graph Models; Online Relations 


\section{Introduction}

3 Historically, movement scholarship and lay discourse around social change have suffered from a

4 tendency to treat social movements as single, unified entities. While it is a matter of convenience

5 to refer to whole movements as "the" movement, this obfuscates their internal processes (Meyer \& Corrigall-Brown, 2005; see also Touraine, 1981; Melucci, 1996). In reality, movements are amalgamations, phenomena that are comprised of "internally differentiated actors operating

8 within complex social settings..." (Ruct, 2004, p. 197). Of these actors, Social Movement Organisations (SMOs), my focus here, are united by various relations, among which alliances an ad-hoc and largely informal type of "means oriented" cooperation (Tarrow, 2005, p. 163) understood to exist anytime two or more SMOs work together around a common task (van Dyke \& McCammon, 2010) - is only one. ${ }^{3}$ Scholars taking a network perspective (c.f. Diani,

13 Forthcoming; Mische, 2008; Wang \& Soule, 2012; see Diani \& McAdam, 2003 for a review)

14 have successfully argued against holist thinking and lobbied for the more appropriate

15 conceptualisation of movements as a constellation of both $\mathrm{SMOs}^{4}$ and individual activists.

16 However, since Gould's (1991) classic exploration of overlapping ties among insurgents in the

171871 Paris Commune, there has been little further acknowledgement of co-occurring relations in 18 social movements, particularly amongst SMOs. ${ }^{5}$ Given the range of ways through which these 19 organisations may be simultaneously directly and indirectly tied, my concern here is the scant

20 systematic and empirical exploration of the role of concurrent relations in the establishment of

21 alliances between these strategic actors.

Here I focus on the structure of alliance networks between SMOs and my principal empirical

24 task is to uncover the degree to which co-occurring relations help explain their emergence. In the 25 most basic sense, social systems may be conceived of as a number of heterogeneous actors tied

\footnotetext{
${ }^{3}$ Broadly, relationships between SMOs range from those that are informal and largely ad-hoc to fusion via mergers (c.f. Cornfield \& McCammon, 2010). While this heuristic is problematised in light of new relations that are digital in nature (e.g. following on Twitter, or liking on Facebook), they provide a tractable framework for theorisation. Note that for the purposes of this work, "coalition relationships" refers to the entirety of this relational spectrum.

${ }^{4}$ I use Zald and Ash's (1966) classic definition of social movement organisations as organisations with goals aimed at changing society. These organisations ultimately wish to restructure society and/or the state of individuals or maintain the status quo as opposed to only existing to offer a regular service, such as in bureaucratic organisations.

${ }^{5}$ Diani (2003, p. 314), Baldassarri and Diani (2007), and McAdam and Paulsen (1993) are notable exceptions.
} 
1 together via a broad range of social and economic relations. For any two actors, the ties which may bind them are diverse, representing, for example, positive feelings/affirmation (friendship, love, affiliation), communication/information exchange, the exchange of goods and capital (trade) or behavioural interaction (cooperation or punishment). Each of these relational contexts may be regarded as an individual network, however, they all influence and co-construct one another - each network acting as a constraint or an enablement. Thus, society is characterised by "the superposition of its constitutive socio-economic networks, all defined on the same set of nodes" (Szell et al., 2010, p. 13636). This superposition is called multiplexity (Figure I). ${ }^{6}$

\section{[Insert Figure I —Slices of a Multilayered Network]}

Figure I | Slices of a Multilayered Network: Simplex view of relationship one (A), simplex view of relationship two (B), and multiplex view of both relationships (C).

In light of the mulstistranded nature of socio-economic relations, I ask in what ways and to what degree is alliance formation governed by multiplexity? To answer this question I draw from work in organisational studies to explore multiplex network configurations as key determinants of alliances in social movement organisational fields ${ }^{7}$ — populations of interdependent SMOs

19 oriented towards a similar set of issues who are tied together in a network structure chiefly

20 dependent upon patterns of domination and cooperation, information exchange and mutual

21 awareness (Minkoff \& McCarthy, 2005). Maintaining that contemporary accounts of

22 multiplexity within social movement scholarship must move beyond simple acknowledgment to

23 forge an explanatory, inferential understanding of the role of co-occurring ties, I argue that: (a)

24 alliances between SMOs and the other relational contexts within which these actors are

\footnotetext{
${ }^{6}$ Multiplex relations are also known as multirelational, multimodal, multivariate and multistranded in the social sciences.

${ }^{7}$ Note that in the most holistic sense, organisational fields include both the focal actors of interest, here SMOs, and those other organisations they routinely interact with, such as governmental agencies and opposing groups, in addition to grassroots organisations. Here I only explore relations between SMOs, using the phrase social movement organisational fields to distinguish populations of only SMOs from the larger set of actors work in this area typically addresses. Additionally, I do not give treatment to configurations of individuals and SMOs as populations of SMOs represent a unique aspect of movements which require inquiry into processes that are supra-individual (Zald \& McCarthy, 1980). In this regard, social movement organisational fields may be viewed as equivalent to social movement industries (McCarthy \& Zald, 1977), however, here the notion of field is favoured due to its more explicit connotation of relational processes (see DiMaggio \& Powell, 1983).
} 
1 embedded (e.g., information exchange, positive nomination, tactical advice giving, project

2 collaboration) are characterised by manifold interdependencies; and thus (b) to avoid the biased

3 understanding of social systems that comes with simplex (i.e., single relation) analyses, alliance

4 formation must be investigated alongside concurrent ties. Here multiplexity is treated as given,

5 using it as a tool for unravelling the puzzle of emergence. This positions the alliance network

6 itself as the dependent variable to be explained.

8 Notwithstanding, multiplexity is not the sole determinant of alliance. In addition to social ties a number of other factors have been linked to coalition formation. Broadly, these include the

10 (in)congruence of ideology/interest (Croteau \& Hicks, 2003), contender perceptions (Kadivar,

11 2013) and socio-political threat (McCammon \& Campbell, 2002). ${ }^{8}$ Recast within classical

12 movement theories, these factors address issues around political opportunity structure (Kriesi,

13 2004), resource mobilisation (Jenkins, 1983), and collective identity/frame alignment (Benford

$14 \&$ Snow, 2000). Owing to classic treatment of movements as singular and/or homogenous

15 entities, scholars focusing on coalition relations have traditionally analysed the importance of

16 these factors at the level of the individual organisation, i.e., properties of the actor itself such as

17 resources, age and ideology, as opposed to the interplay of these attributes and structure. While

18 the acknowledgement of exogenous, non-network, properties helps relax quite strong

19 assumptions about self-organisation in social systems endemic to more engineering and physical

20 sciences approaches to networks, understanding of the formation of social relations is limited

21 when dependencies at the structural level, orders increasingly higher than individual actors, are

22 unaccounted for. Thus my goal is not to suggest that social ties alone are adequate for the

23 complete exposition of the processes which govern the formation of alliances between SMOs.

24 Instead, I simply seek to empirically demonstrate that there are complex, multiplex dependencies

25 at the level of the network which movement scholars focused on alliance formation have yet to 26 address.

28 The empirical context chosen for the exploration of these ideas is the forging of online alliances,

29 in the form of hyperlinks (see Park et al., 2004; Pit et al., 2006; Rogers \& Marres, 2000),

\footnotetext{
${ }^{8}$ See van Dyke \& McCammon (2010) for a review of these and other factors.
} 
1 between the websites of professional SMOs. The world has seen the proliferation of collective

2 actions with notable Internet dimensions in recent years. While the degree of political and

3 democratic efficacy afforded through use of the Internet is still hotly debated, contemporary

4 instances of collective action necessitate a focus on the role of the Internet in facilitating

5 relations which bind political actors (c.f. González-Bailón, Borge-Holthoefer, Rivero \& Moreno,

6 2011) and thus comprise, in part, the structure of social movement organisational fields in an

7 information society (Garrett, 2006). Lest I unduly suggest equivalence between traditional

8 movement alliances, with their expectation of the investment of material and symbolic resources

9 and their ability to facilitate long-term commitment, and online alliances, which are informal and

10 asymmetric whilst intrinsically imposing no immediate obligations for those involved, the nature

11 of hyperlinks relative to traditional social movement alliances must be addressed.

13 In crafting my understanding of online alliance I draw heavily from Rogers (2013), viewing the

14 network constituted by hyperlinks as representative of an associational space ${ }^{9}$. Importantly, this

15 space is constructed via organisations' purposive creation of hyperlinks to signify with whom or

16 what they wish to be affiliated (see Lusher \& Ackland, 2011; Pilny \& Shumate, 2012; Shumate

17 \& Lipp, 2008; Weber, 2012). In these systems of representational communication (Shumate,

18 2012) the acts of making, not making, or removing hyperlinks are political in that they have

19 implications for the construction of organisational reputation. Hyperlinks serve as doors from

20 one website to another through which users traverse, and make sense of, the structure of the

21 Web. The opening and closing of these digital pathways by SMOs may facilitate the construction

22 of collective identity (Ackland \& O'Neil, 2011) and contribute to the collective visibility of

23 movement actors (Shumate \& Dewitt, 2008). Ultimately, from this perspective hyperlinks

24 represent a means of constructing categories and establishing boundaries. Thus to the extent that

25 SMOs: (a) actively manage their personas and; (b) are cognisant of public understanding of

26 organisational identity by means of comparison to others, the creation, maintenance and

\footnotetext{
${ }^{9}$ The original notion of an associational space or "issue network" (Rogers 2010a; 2010b) includes hyperlinks between social actors and inanimate objects (e.g., a hyperlink from an organisational website to a specific webpage such as the Wikipedia entry on flat organisational forms). Here, I only consider direct hyperlinks between organisational actors as they position themselves next to one another. Ackland (2013; p. 82) provides an overview of different disciplinary perspectives on hyperlinks.
} 
1 modification of hyperlinks are understood to reflect the strategic communicative choices and agendas of actors (on such strategy see Dysart, 2002; Garrido \& Halavais, 2003; GonzálezBailón, 2007; Kleinberg \& Lawrence, 2001; Park, 2002; Tremayne, 2004). ${ }^{10}$

5 Bivariate exponential random graph models (ERGMs) are used to explore the relationship between online alliance and digital proxies for shared allies (co-followers on Twitter), information exchange (Twitter Friend/Follower Graph) and positive nomination (Likes between

8 SMO Facebook pages), and offline co-lobbying activity (joint meetings with government minsters) at the dyadic, degree and triadic levels. Data come from the associational practices of

11 campaign around public sector cuts in the UK and their adverse effects on the disabled.

13 To be sure, the relationships explored here are not redundant, which would indicate that

14 movement scholars simply need to more accurately count the number of relations in dyads

15 (Gould, 1991). Instead, results indicate that multiplexity, as exhibited by cross-network

16 dependencies in various local-level configurations of ties, plays a non-trivial role in the

17 formation of alliances and, more generally, social movement organisational fields. Large

18 tendencies for alliance to co-occur with both expressive and instrumental ties suggest that

19 embeddedness, and the trust it breeds, are key components of alliance formation at the dyadic

20 level. Furthermore, this layering of alliance onto other relations may be thought of as a strategy

21 to manage risk when information is imperfect and a SMO has already invested in another.

23 Moreover, results suggest alliance formation happens in the face of both competition and 24 cooperation over scarce relational resources in social movement organisational fields. The 25 simplex analysis here does indeed indicate that the alliance network is characterised by processes 26 representative of macro-level cohesion (i.e., large propensities for reciprocity and transitivity)

27 which are characteristics of the non-hierarchical organisational forms represented by offline 28 (Baldassarri \& Diani, 2007) and online (Ackland \& O’Neil, 2011) social movement networks. 29 However, cross-network associations between degree distributions indicate that some SMOs

\footnotetext{
${ }^{10}$ See Appendix D for an additional discussion on hyperlinking as an associational practice.
} 
1 engage in opportunistic alliance formation whereby they pool relational resources without establishing alliances with others. This process is, arguably, magnified by strong tendencies for concurrent ties to be entrained with alliance. Substantively, such free-riding may adversely affect the wider integration of social movement organisational fields. With regard to theory, the coexistence of opportunistic and cooperative behaviour suggests that work advancing competing hypotheses about how these seemingly orthogonal processes impact alliance formation (c.f. Okamoto, 2010) must consider how both may operate jointly within and across network layers. ${ }^{11}$

Finally, tendencies for alliance to be embedded in triangles formed with co-occurring ties suggests that signalling, by means of structural position, helps to govern alliance formation in

11 multilayered systems. Specifically, the tendency for a SMO to form an alliance with another

12 SMO with whom it positively nominates the same third other and/or with whom it is positively

13 nominated by the same third other compared to a tendency against the formation of an alliance

14 with a SMO that is indirectly positively nominated, suggests a form of uncertainty reduction.

15 Here, SMOs privilege direct confirmation of identity-based similarity vis-à-vis choice of

16 expressive partners over the imperfect information of the latter scenario.

18 The outline of the remainder of this work is as follows: I first build a uniquely relational

19 understanding of alliance formation that sits at the intersection of social movement and

20 organisational studies (Sections 2 and 3). Given that social movement alliances have received

21 little empirical attention (van Dyke \& McCammon, 2010) in addition to the interdisciplinary

22 nature of my argument, I give an extended treatment of past research on alliance, multiplexity

23 and inter-organisational networks for contextualisation. This is then followed by hypotheses

\footnotetext{
${ }^{11}$ Here, "instrumental" and "expressive" are used to describe the nature of the relation that some actor may create whereas "cooperative" and "opportunistic" are used to describe the logic in which ties of both type may be established when considering their patterning within and across network layers. These two sets of categories are not orthogonal, such that network structure may suggest a cooperative logic in the establishment of instrumental ties and vice versa.

To make the difference between cooperative and opportunistic logics more concrete, consider the cyclic triad and the reciprocated dyad, sub-graphs archetypal of exchange whereby all actors stand to benefit. These structures stand in stark contrast to those which allow some actor to exploit their structural position at a loss for other actors. For example, consider sub-graphs in the form of unclosed triangles and chains wherein structural position may afford an actor the ability to control resources flows (e.g., brokerage, in the case of the unclosed triangles, or penultimate actors on shortest paths, in the case of chains; see Brandes, 2008).
} 
1 (Section 4), the presentation of the case study, data and methods (Section 5), and a substantive 2 discussion (Section 7) following results in Section 6.

\section{Social Ties and Movement Alliances}

Scholarship at the intersection of alliance formation and social ties has largely emphasised the 8 importance of "coalition brokers" or bridge builders - individuals in the form of leadership or membership who span organisations - in building coalitions (Bystydzienski \& Schacht, 2001;

10 Ferree \& Roth, 1998; Obach, 2004). These individuals have been found to play a critical role in 11 bridging class (Rose, 2000) and racial (Grossman, 2002) divides. Yet, these metaphors are 12 rooted in network theories of brokerage and closure (Burt, 1992; Granovetter, 1973), and use of

13 these concepts in the absence of empirical studies of networks has led scholars in this area to fail

14 to offer a systematic account of their foundations - network structuring processes driven by 15 complex dependencies in multilayered social systems. The appropriation of network metaphors

16 without the network itself has serious implications given the complexity of social systems and

17 the multiple processes leading to their formation (Monge \& Contractor, 2003). ${ }^{12}$

Two issues, scale and context collapse, perpetuate the use of network metaphor in the absence of substance in previous work. The first relates to the level of analysis. Despite social relationships 21 influencing perceptions of potential allies (Rose, 2000), scholarship on coalition relations has

22 largely focused on how factors at the level of the actor (e.g., resources and ideology) and factors 23 external to those under study (i.e., political opportunity structure/environment) affect coalition

24 formation. This removal of actors from the relations which tie them precludes precise accounts 25 of processes at the structural level as ties are written off. The second sees the implicit projection 26 of multiple layers onto a single one. This may largely be attributed to a one dimensional view of 27 boundary spanning actors as the only social tie of concern outside of the alliance itself (c.f. Osa, 28 2003; Arnold, 2011 and Park, 2008 provide alternatives). Such an approach effectively neglects 29 the array of ways in which organisations may be directly and indirectly tied within and across

\footnotetext{
${ }^{12}$ See McAdam and Paulsen (1993) for an analogue discussion of the use of network metaphor over substance in work on the importance of social ties for activist recruitment.
} 
1 multiple networks. Together, issues of scale and context collapse leave a number of unanswered 2 questions: What structural positions are most conducive to the receipt of allies? How does the

3 alignment and trade of ties across networks influence alliance formation? How do alliances form

4 in the face of mutual selection of (agreement) and mutual selection by (co-citation) third others

5 across different layers of a network? How might the receipt of various social relations influence

6 a SMO's willingness to form alliances with others?

8 Diani (1992) has extensively outlined the importance of the relational aspect of social movements, ultimately positioning them as organisational fields (Diani, 2013; also see Minkoff

$10 \&$ McCarthy, 2005). This positioning is crucial as it allows one to acknowledge and analytically

11 account for the existence of heterogeneous actors who possess varying levels of resources,

12 harbour different interests and identities, operate under various exogenous constraints, and are

13 tied together via a number of relations in addition to overlapping membership and shared allies.

14 From this perspective, both a multilevel (i.e., multiple levels of nested structure) and multiplex

15 understanding of social movement organisational fields is crucial for the most complete

16 understanding of the dynamics of alliance formation. Unfortunately, the somewhat niche

17 literature on social movement coalition relations is, at best, vague as to what structural factors

18 lead to the formation of simplex alliance networks, much less multiplex inter-organisational

19 networks. Therefore, I now turn to scholarship in organisational studies, in addition to work on

20 civic networks, where scholars have actively addressed these two issues.

\section{Multiplexity and Inter-Organisational Networks}

Uniting insight from classic work in the social sciences on overlapping relations in dyads (Gluckman, 1962; Kapferer, 1969; Vebrugge, 1979; Wheeldon, 1969) and more recent work in mathematics and physics on the non-trivial coupling of multiple layers of distinct relations in systems (De Domenico et al., 2013; Gómez-Gardenes et al., 2012; Kivelä et al., 2014), I define multiplexity as overlapping relations between a set of actors whereby; (a) each relation forms a

30 distinct layer of a larger system of interest; (b) layers are beholden to emergent processes which 31 may differ from other layers; and (c) combinations of ties across layers may interact in non- 
random ways. As much of social network research makes clear, layers may be usefully analysed in the absence of others. However, layers are often interdependent and collectively shape network structure (Cardillo et al., 2013). Ignoring this limits understanding of the complexity of social life as it produces an incomplete picture of the embeddedness of actors and their relations (Ferriani, Fonti, \& Corrado, 2013; Zhao \& Rank, 2013). This is because one tie, while forming a unique relational context, often entails another (Shiplov \& Li, 2012; White, 2008). To the large extent that networks provide valuable insight into human social systems, these distortions

8 seriously hamper understanding of the behaviour of individual actors in groups.

Scholars from organisational studies have convincingly argued for the importance of multiplexity in light of the potential bias of simplex analyses (c.f. Lomi \& Pattison, 2006). As Kenis and Knoke (2002) state, an organisational field cannot be reduced to a single network as a number of ties are relevant to an explanation of its structure. Thus groups of organisational actors

14 are bound by manifold interdependencies within and across the layers of the network within 15 which they are embedded (Lazega \& Pattison, 1999, Rank, Robins \& Pattison, 2010). Laumann, 16 Galaskiewicz and Marsden (1978) identify two types of inter-organisational relations which may

17 operate simultaneously: (a) those based on the transfer of resources; and (b) those which

18 interpenetrate organisational boundaries. While both resource-based and interpenetrative relations are understood to be chiefly instrumental, "relations involving boundary

20 interpenetration often have an additional component of solidarity maintenance" (Laumann et al., 21 1978, p. 463). As discussed in Section 2, scholarship on social movement coalition formation has

22 focused most intensely on boundary spanning relations via brokers. Still, overlapping

23 membership is only one of a number of types of ties between organisations, which may include

24 transfer of a number of resources, project collaboration, joint participation in meetings and

25 forums, and interlocking directorates, among others (c.f. Katz \& Anheier, 2006).

27 Each of these relations can be categorised based on the extent to which they are instrumental or expressive. In a study of civic organisations, Baldassarri \& Diani (2007) note that these groups

29 may limit their relations with others to the instrumental exchange (e.g., sharing material

30 resources) necessary for action that, in the case of SMOs, is aimed at creating some normative

31 condition or change. On the other hand, organisations may be tied via expressive connections 
1 that are affective and carry deeper obligation (e.g., overlapping membership). This is in contrast

2 to instrumental exchange which is characterised by its ad-hoc and temporary nature. Despite

3 expressive ties being more likely to lead to the formation of additional relational contexts

4 between actors over and above instrumental relations due to their affective basis (Ferriani et al.,

5 2013), both must be accounted for to yield the most complete understanding of the dynamics of

6 inter-organisational networks.

8 Baldassarri and Diani (2007) argue that multiplexity, as indicated by the simultaneous existence

9 of various instrumental and expressive ties between civic organisations, perform a joint micro-

10 macro integrative role. Following their logic, should a civic network be driven entirely by

11 expressive exchange it would tend to fragment into non-overlapping clusters of ideologically

12 similar organisations. However, should an instrumental logic dominate, these networks would

13 take a disorganised form antithetical to the micro-level cohesion characteristic of solidarity

14 whereby ties are created "according to 'quasi-random' criteria, with weak constraints on partner

15 selectivity" (Baldassarri and Diani, 2007, p. 768). Comparing macro and micro-level features of

16 observed networks (e.g., average path length and balanced interconnectedness in triads) to those

17 of randomly generated networks, Baldassarri and Diani found that civic networks are comprised

18 of organisations embedded in dense clusters of expressive ties which are united by global bridges

19 in the form of instrumental exchange. This integrative logic is preluded by Wellman (1983) who

20 maintains that the absence of ties across different sub-graphs in a network may lead to distinctive

21 subcultures. Clustering, driven by transitive closure, leads to "bounded factions and coalitions"

22 (Wellman, 1983; p. 178) and cross-linkages between clusters are understood to offer the

23 structural foundation for macro-level integration. Wellman argues that the absence of these

24 global bridges may have been the reason for the failed coalition by the Italian-American

25 residents of Boston's West End in their efforts to put a halt to destructive slum clearance 26 activities.

28 Key to this integrative process is the manner in which multiplexity functions in dyads and triads.

29 While Baldassarri and Diani (2007) addressed two classes of relations (expressive exchange,

30 which they call "social bonds", and instrumental exchange, which they label "transactions"), the

31 authors effectively collapse multiple types of ties into two categories. While conceptually useful, 
1 this projection obfuscates the distinctiveness of each relation, each layer, as indicated by their

2 different structuring logics, and any unique understanding from their joint analysis is lost.

54 Hypotheses

7 Work on civic networks directs attention to cross-network processes located in dyads and triads.

8 Focusing on these substructures, I advance the following hypotheses about alliance formation 9 and multiplexity.

11 Hypothesis I - In dyads, multiple layers of dependence and exchange will impact the likelihood 12 of alliance formation.

14 The most basic association between two digraphs occurs at the dyadic level in the form of 15 entrainment and exchange. Theories detailing these two associations are largely rooted in work 16 on the embeddedness of economic action within social structure (Granovetter,1985), relational

17 embeddedness (Gulati \& Gargiulo,1999), exchange (Homan, 1950; 1974) and resource

18 dependency (Blau, 1964). Entrainment represents the degree to which directed ties co-occur

19 within dyads. In the case of two actors, $i$ and $j$, embedded in two layers, e.g., perception of

20 reliability and money lending, entrainment occurs when actor $i$ nominates actor $j$ as reliable in

21 addition to lending actor $j$ some sum of money. Additionally, another degree of entrainment

22 would be present if $i$ and $j$ were formal business partners. Exchange represents the trading of

23 connections of different types across dyads. In an exchange scenario actor $j$ would return her

24 loan to $i$ who would then nominate $j$ as trustworthy.

26 Hypothesis II - In triads, instrumental and expressive ties to and from candidate alliance

27 partners by way of third-others in co-occurring networks will impact the likelihood of alliance 28 formation.

30 Beyond dyads a comprehensive body of research has addressed configurations of three actors in 31 work on network closure. In the context of inter-organisational networks, closure has largely 
1 been interpreted as "a direct consequence of the costs and risks inherent in the formation and maintenance of network ties with partners whose quality, capability, and trustworthiness are only imperfectly observable" (Lomi \& Pallotti, 2013, p. 202). From this perspective, shared partners are a source of trust, legitimacy and reliability (Granovetter, 1973; 1985; Gulati, 1995; Uzzi, 1996). The ties which directly link those connected via multiple third others are understood to be structurally embedded (Gulati \& Gargiulo, 1999; Riviera, Soderstrom \& Uzzi, 2010). For simplex digraphs, Robins, Pattison and Wang (2009) identify four possible types of closure

8 based on the arrangement of ties in triangles, which consists of a top (2-path, in-2-star or out-2star) and a base (the structurally embedded arc). Specifically, these four types of closure are: (a) activity closure, whereby a form of structural equivalence based on shared outgoing ties to the

11 same third others induces the formation of the structurally embedded arc; (b) popularity closure,

12 whereby a form of structural equivalence based on shared incoming ties from the same third

13 others induces the formation of the base of the triangle; (c) transitive closure, whereby indirect

14 connections from $i$ to $j$ induces the establishment of the embedded arc $i j$; and (d) cyclic closure, a

15 form of generalised exchange whereby the indirect receipt of ties from $i$ to $j$ induces the 16 embedded arc $j i$.

\section{[Insert Figure II — Forms of Closure In Multiplex Networks]}

Figure II | Forms of Closure in Multiplex Networks: Dashed lines represent the tops of triads involving ties to/from/between candidate alliance partners ( $i$ and $j$ ) via multiple third others $(\mathrm{k})$ in cooccurring networks (B). Solid lines represent hyperlinked alliance (A). The codes in parenthesis are the identifiers used to specify a multivariate ERGM in XPNet. Reproduced with permission from Gijs Huitsing.

Given the role of closure in simplex scenarios it is not unreasonable to expect it to be a prominent feature of multilayered networks. Building on work demonstrating that embeddedness has implications for transitivity (Gulati, 1995; Gulati \& Gargiulo, 1999), Lee and Monge (2011) advance the notion of "embedded transitivity" whereby multiple common third party ties between two organisations in one network lead to the formation of a tie in another. While these authors focused only on undirected relations, thereby reducing the four types of cross-network closure to one triangle with three symmetric ties, Huitsing et al. (2012) maintain the directed 
1 configurations of Robins et al. (2009) to generalise the four types of closure to a multiplex scenario (Figure II). I utilise each type of multiplex closure to model alliance as a relation structurally embedded in triangles composed of some other co-occurring relation. To also gain a more holistic understanding of the association between alliance and the co-occurring relations under study, I explore associations at the degree level via multiplex mixed-2-stars, in-2-stars (popularity) and out-2-stars (activity). Table I gives the network configuration and a short description for all simplex and multiplex configurations utilised in this work.

\section{[Insert Table I — Parameters for Univariate and Bivariate ERGMS]}

\section{Data and Methods}

\subsection{Health in Austerity: The Case of the UK Anti-Cuts Movement of the Disabled}

Here I adopt the UK anti-cuts movement as a case study for exploring the role of multiplexity in the formation of online alliances. Broadly speaking, grievances expressed over public sector cuts

17 in the UK are embedded in a much larger transnational wave of contention around anticapitalism in the wake of the 2008 global financial crisis (Calhoun, 2013 provides a summary of events). As prominent drivers of the narrative around socio-economic inequality, aspects of the revolutions in the Middle East and North Africa, the Indignados in Spain, protests in Greece, and the Occupy Movement in the US can be found within the UK anti-cuts movement. Indeed, one may even trace the roots of the contemporary incarnation of the anti-capitalist imperative to the 1994 Zapatista rebellion in Chiapas, Mexico, or the "Battle of Seattle" anti-WTO demonstrations

24 in 1999. Despite media and lay attention emphasising the role of the more visible Occupy, in the

25 UK groups of varying degrees of institutionalisation, such as UK Uncut, the Trades Union

26 Congress and Keep our NHS Public, gained more traction with activism around the perils of

27 neoliberal austerity.

The heterogeneous nature of the UK anti-cuts movement makes it a very fruitful case for inquiry;

30 however, analytically, that same diversity raises important issues around boundary specification.

31 The valid identification of boundaries is crucial for defensible network analysis. This is 
1 particularly true for ERGMs where the projection of estimates obtained from models of sampled networks to some global network of interest has been shown to be erroneous (Shalizi \& Rinaldo, 2013). ${ }^{13}$ To mitigate this issue, I focus on a sub-division of the broader UK anti-cuts movement that sits at the intersection of public sector cuts, access to health resources and the rights of the 5 disabled. Specifically, I use the 55 health-related SMOs of the Hardest Hit Campaign (HHC). ${ }^{14}$ Begun in 2011, the HHC was launched to raise awareness of the needs of the disabled and bring about change in the form of a fair UK benefits system. Organisers of the HHC consists of the

8 Disability Benefits Consortium (DBC) ${ }^{15}$, an association of 54 charities and advocacy organisations and the UK Disabled People's Council.

11 There are a number of benefits and caveats associated with use of the HHC. With regard to 12 boundary definition, the HHC is a set SMOs that is clearly identifiable in membership and focus. 13 As it would be unreasonable to expect to comprehensively account for all SMOs active in the 14 UK anti-cuts movement, a clearly demarcated set of actors is very advantageous. However, it is 15 important to note that focusing on this sub-section of the anti-cuts movement requires 16 characterisation of the present analysis as one of alliance formation amongst members of 17 specific issue campaign, as opposed to alliance formation in the throes of mobilisation at the 18 level of a movement. This shift in focus means that analyses of networks comprised of a more 19 expansive cross-section of the anti-cuts movement's organisational actors could potentially see 20 additional patterns in alliance formation emerge or, potentially, different dynamics all together.

22 A related issue lies with the potential predisposition of the organisations under study to cooperate 23 given that 54 out of the 55 SMOs are members of the DBC, a large-scale coalition itself.

24 However, even within large-scale coalitions, relations amongst members are differentiated 25 (Arnold, 2011). Further still, participation is not universally beneficial as the organisational

\footnotetext{
${ }^{13}$ Advances around estimation using snowball sampled networks and networks with substantial portions of missing data (see Koskinen, Robins, Wang \& Pattison, 2013) are not currently available for bivariate ERGMS.

${ }^{14}$ http://thehardesthit.wordpress.com/about/

15 The earliest report made available online by the DBC (http://disabilitybenefitsconsortium.wordpress.com/2011/03/) lists 41 organisational members as of March 2011. Coincidently, this is also the first post by the DBC on its website. Of the 41 SMOs, 40 were still members of the DBC (http://disabilitybenefitsconsortium.wordpress.com/dbc-members/) and HHC at the time of data collection. While this is not definitive evidence for the age of the DBC, it seems fair to say that both the HHC and the DBC of 2013 are well established entities that have seen little fluctuation in membership from 2011.
} 
1 maintenance required for long-term political survival leads coalition members to compete with

2 one another for resources and differentiate (Hathaway and Meyer, 1993). Thus there is no $a$

3 priori reason to assume collaboration precludes competition. To be sure, results (Section VI) do

4 indicate that there are competitive processes at play in the organisational field constituted by the

555 SMOs of the HHC.

7 Furthermore, it must be said that the benefits around analysing this clearly identifiable group are 8 weighed against the utility of having a more diverse study population with regard to degrees of 9 radicalism, i.e., left-wing anarchist/right-wing conservative groups versus bureaucratic 10 organisations. Given their charitable status, the HHC SMOs are most appropriately categorised 11 as professional SMOs - staff driven entities devoted to political or legal advocacy, or technical 12 support that derive their resources from institutions and isolated constituencies, and represent, 13 rather than directly mobilise, their beneficiaries (Jenkins, 1998). This is in contrast to indigenous

14 SMOs which are heavily involved in face-to-face organising and derive the bulk of their support 15 from their movement's beneficiaries. This latter group best characterises the most visible activist 16 organisations of the UK anti-cuts movement (e.g. Occupy, UK Uncut).

18 A similar concern lies with the ability to classify the 55 organisations as SMOs, nonprofits or 19 interest groups. Scholars such as Císař (2013) have argued that there are notable differences

20 between SMOs and interest groups, particularly for those SMOs that are radical and/or 21 countercultural in nature and those interest groups that exclusively serve commercial interests.

22 Notwithstanding, here I subscribe to the view of Andrews and Edwards (2004) who maintain that 23 divisions between these three classes of organisations are porous. While the present analysis 24 emphasises the social movement dimension of the HHC's members, it is important to note their 25 difference from those organisational actors typically studied in the sociological literature on 26 social movements (e.g. the grassroots SMOs of the civil rights or environmental movements).

28 Ultimately the benefits gained from a clearly bounded group of actors relative to the sensitivity 29 of ERGM results to demarcation, alongside the fact that health-related social movements are 
1 relatively understudied (Brown \& Zavastoski, 2004), make the HHC a useful case study despite

\section{$5 \quad 5.2$ Co-Occurring Networks of Interest}

Positive Nomination: Affective ties between organisations provide social support, establish a 8 sense of identity and belonging and transmit normative expectations (Umphress, Labianca, Brass, Kass \& Scholten, 2003). As a tool for social movement actors, Facebook has traditionally

11 effective information hubs for the purposes of mobilisation (e.g., knowledge exchange amongst

12 movement adherents about protests or discussion of movement grievances; c.f. Harlow, 2012,

13 Gaby \& Caren, 2012) and the distribution of counter-narratives (Cammaerts, 2012). Here I take a

14 different approach and employ the web of affective nominations between organisations'

15 Facebook Pages when one organisation uses a social button to "Like" another. Facebook

16 introduced the ability to "Like" content in 2009 as an activity geared to replace short affective

17 proclamations such as "Awesome" (Pearlman, 2009). As Gerlitz and Helmond (2013) argue,

18 "the [Like] button provides a one-click shortcut to express a variety of affective responses such

19 as excitement, agreement, compassion, understanding, but also ironic and parodist liking" (p.

20 1358).

22 Given their affective nature, Liking amongst SMOs may influence perceptions of closeness, 23 making them apt for establishing (sub)movement boundaries around collective identity (see 24 Arnold, 2011). A need then arises to qualitatively distinguish Facebook Likes from hyperlinks, 25 which also enable the maintenance of identity and boundaries amongst SMOs. Relative to the 26 argument I advance here, the key difference between Facebook Likes and hyperlinks is the 27 latter's primary existence as functional. Hyperlinks principally serve to move an Internet user 28 from website A to website B, structuring the content of the Web (see Broder et al., 2000). While 29 Likes do establish doors between organisations' Facebook Pages, the formation of pathways is

\footnotetext{
${ }^{16}$ See Appendix A for a list of the 55 SMOs
} 
1 the central purpose of hyperlinks. ${ }^{17}$ This enables a conceptualisation of hyperlinks as a form of

2 alliance as organisations are understood to actively use these digital ties to position themselves

3 next to one another online. Further still, amassing a large number of inbound hyperlinks may

4 result in an organisation's increased online visibility by indicating the importance of its website

5 to search engine algorithms (Ackland \& O'Neil, 2011). Such a practical element is wholly absent

6 from Likes between organisations' Facebook pages which I view as purely expressive given the

7 affordances of Facebook as a platform and the original intent behind the introduction of "Likes".

8 Importantly, the functional and practical aspects of hyperlinks are likely to contribute to the

9 formation of a structure that is distinct from that which is built from Likes, despite the duality of

10 both types of ties. This justifies treatment of the hyperlink network as unique.

12 Finally, there is one important caveat to my use of Likes in this work. The conceptualisation of

13 Liking as an affective action has been exclusively advanced relative to individuals' interaction

14 with content on Facebook and there is no a priori definitive way to know that a Like is positive

15 in nature. With that said, the rhetoric of sociality and engagement that is characteristic of

16 Facebook as a platform (Gerlitz \& Helmond, 2013) alongside the collaborative logic uniting the

17 organisations under study here allows Liking to be positioned as an affective action

18 representative of positive nomination.

20 Information Exchange: While information exchange is a social tie in the strictest sense, I use

21 public-facing information exchange to relax expressive assumptions that might come with other

22 exchanges of this kind such as gossip. Given its status as a cornerstone of activists' digital

23 communication strategies (see Theocharis, 2013 and Tremayne, 2014; also see Bennett,

24 Segerberg \& Walker, 2014 on Twitter as an integrative link that ties together the macro-level

25 structure of multiplex protest networks) and the absence of a technical requirement for, or

26 expectation of, reciprocity (Marwick \& boyd, 2010), I use relationships on Twitter as proxies for

27 instrumental information exchange.

\footnotetext{
${ }^{17}$ A Like between Facebook Pages serves as a type of platform-internal hyperlink. At this time, the list depicting the set of organisations that a focal organisation Likes allows an Internet user to move from the Page of the focal organisation to the Page of some organisation that has been Liked. However, this method of traversing Facebook has not historically been central to user engagement. This is in contrast to the foundational role hyperlinks play in structuring the Web with regard to user experience and the organisation of content.
} 
1 Ultimately, I take what is itself an instrumental perspective on these relations and see them as 2 primarily constituted by what fundamentally flows through them - news largely propagated by

3 broadcasters (Kwak, Lee, Park \& Moon, 2010). This understanding is in line with scholarship

4 approaching Twitter as a tool for direct communication and it is largely coloured by arguments

5 against utopianism around and centrism of online communication platforms relative to social movements and social change (see Diani, 2000) and society more generally (see Mansell, 2012;

7 Morozov, 2011). Essentially, the view of Twitter subscribed to here focusses on the platform's

8 facilitation of weak ties and emphasises its most basic and uncontested dimension - the ability

9 to move information from some content producer to consumer. Note that Twitter's architecture

10 enables actors $i$ to follow actors $j$, leading to a situation where actors $i$ are automatically

11 presented with all public content produced by actors $j$ via their news feeds. While, technically,

12 information flows from $j$ to $i$, I retain the direction of these relations as dictated by the platform,

13 i.e., from $i$ to $j$, in order to have the network reflect the agency of SMOs in their choice of

14 information sources as opposed to the flow of information.

Activist Dependence: As past scholarship on social movement coalitions makes clear, the duality

17 of persons and groups (Breiger, 1974) created by shared allies between SMOs is a key component of alliance formation. For organisations dependent upon voluntary work, and thus the commitment of (in)formal membership, the ties created by activists' support of multiple organisations suggest connections stronger than purely instrumental exchange (Baldessarri \& Diani, 2007). Following the same rationale for the use of Twitter as a proxy for information exchange, I use co-followers on Twitter as a proxy for individuals' support of multiple organisations. While shared support between SMOs creates a bipartite structure, I collapse these two-mode configurations to valued symmetric relations between SMOs representative of the number of supporters they have in common. However, assuming that the importance of the raw number of shared supporters between any two SMOs is the same for both parties is unreasonable.

27 I account for this by drawing connections between any two SMOs based on the ratio of their shared supporters to each SMO's total supporters. Specifically, for every dyad, a directed connection $X_{i j}$ is established from $i$ to $j$ if $\varphi_{i}$ - the ratio of $i$ and $j$ 's shared supporters to $i$ 's total 30 supporters - is greater than $\varphi_{j}$ (Eq. 1). 


$$
X_{i j}=\left\{\begin{array}{l}
1 \text { if } \varphi_{i}>\varphi_{j} \\
0 \text { otherwise }
\end{array}\right.
$$

3 The assumption here is that when shared supporters represent a sizeable proportion of an SMO's individual supporters this SMO effectively supports those organisations with whom it shares a

5 substantial number of activists.

Co-Lobbying Activity: Attempts by movement actors to raise awareness and collect allies

8 amongst the political elite and bring about new policies and legislation are fundamental aspects

9 of movement success (Tatterstall, 2010). With regard to alliance formation, joint-meetings with

10 politicians may be viewed as instrumental collaborative ties between SMOs as they jockey for

11 legitimacy and social change. Here I construct a continuous co-lobbying matrix where the scalar

12 at the intersection of the $i$ th row and $j$ th column is a count of the number of times $i$ and $j$ have

13 been co-present at ministerial meetings.

\subsection{Data Collection}

18 I use both data mining and the digital archive data.gov.uk to gather data about the various

19 relationships between SMOs. The hyperlink network was collected in October 2013 by

20 crawling $^{18}$ the websites of all 55 SMOs in the HHC and retrieving the direct connections

21 between each of their websites. For the information exchange network and data on the number of

22 co-followers between SMOs, a program was written in Python to interface with the Twitter

23 Application Programming Interface (API) in January 2014. As the Facebook API does not make

24 certain data available, "Likes" on each SMOs Facebook page were copied manually to individual

25 text files whereby a Python script was used to construct the complete positive nomination

26 network in November 2013. Finally, data on co-lobbying activity comes from publicly available

\footnotetext{
${ }^{18}$ One may analyse the structure of the web using a program referred to as a crawler. Here, hyperlink networks were extracted from the Web using Issuecrawler (http://www.govcom.org/Issuecrawler_instructions.htm), a server-side, parallel web crawling platform for the social scientific analysis of networks of actors around specific themes and topics. Direct hyperlinks between domains (e.g. http://www.macmillan.org.uk/) were extracted by crawling each domain to a depth of three (i.e. from homepage to all sub-pages (1), to all sub-pages found on level one (2), to all sub-pages found on level 2 (3). A maximum crawl of 1000 urls was set for each domain.
} 
1 quarterly transparency reports on UK ministerial meetings. Reports for the UK Department of

2 Work and Pensions, the Department of Health, the Attorney General's Office and the Cabinet

3 Office were collected for the year of 2013. These four departments were chosen due to their

4 substantive relevance to the UK anti-health cuts activists, thus allowing data on co-lobbying

5 activity to reflect SMOs' involvement in debates about issues germane to the HHC.

7 Collectively, data is understood to be a snapshot of the associational practices of the 55 SMOs

8 under study for the year of 2013. A brief comment is warranted on the differences in time covered by the source data for the five relations. While the information exchange, activist

10 dependence, positive nomination and hyperlink networks are collected very near to one another

11 around the last quarter of 2013, the co-lobbying network is comprised from source material

12 spanning the length of the year. Despite this, co-lobbying is a rare event and of those non-null

13 dyads very few see more than two instances of co-lobbying across the year. Density for the

14 binary co-lobbying network is 0.023 , indicating that it is quite sparse. Of the 3025 dyads in the

$1555 \times 55$ weighted co-lobbying adjacency matrix, 42 see one joint-lobbying session, 22 see two

16 joint-lobbying sessions, two dyads see three sessions, and two dyads see five sessions. Given that

17 the majority of non-null dyads saw just one joint-lobbying session across the year it is reasonable

18 to use this relation as a dyadic covariate in the cross-sectional ERGMs.

20 One SMO did not have a profile on Twitter and two did not have profiles on Facebook,

21 representing missing data at the level of the actor. Given the inability of actors to establish

22 connections with those who do not have profiles on these websites, reconstruction and hot deck

23 imputation, as described by Huisman (2009), are not possible. Favouring a more simple

24 procedure due to the percentage of missingness being quite small (1.8\% in the information

25 exchange network and $3.6 \%$ in the positive nomination), I employed Huisman's method of

26 imputation using the unconditional total mean of the network (i.e., average tie value over all

27 observed ties). In binary networks this is equal to the density. Using this method, the rounded

28 value of the density ( 0 if the density is $<0.5)$ is imputed. Effectively, this treats missing ties as

29 absent in sparse networks and present in dense networks. Collectively, data collection yielded

30 four binary asymmetric 55x55 matrices for alliance, information exchange, positive nomination 
1 and activist dependence, and one continuous symmetric 55x55 matrix for co-lobbying.

2 Descriptive statistics for these five networks are given in Table II.

[Insert Table II — Descriptive Statistics]

5 5.3.a Method: Bivariate Exponential Random Graph Models

7 Exponential random graph models are statistical models of network structure which permit 8 inferences about how and why ties arise using a number of structural configurations. These configurations are understood to be reflective of the underlying social processes which create and sustain a social system of interest. I employ bivariate ERGMs to capture configurations

11 which span multiple network layers. The importance of a univariate model relative to a 12 multivariate model in this framework deserves further clarification. Recall that layers span 13 networks of their own which are superimposed upon one another to create a multiplex system.

14 This requires the joint modelling of each univariate dimension of a system alongside multivariate 15 configurations in order to assess, or rather isolate, the role of multiplexity. Practically, this 16 requires quite complex models. However, a key strength of ERGMs as tools for pattern 17 identification is their ability to allow the researcher to test multiple, sometimes competing, 18 theories of network formation (Monge \& Contractor, 2003).

\section{[Insert Figure III — Hierarchy of Lower-order Network Configurations]}

Figure III | Hierarchy of Lower-order Network Configurations: From bottom to top, with arcs

25 Network configurations are nested, wherein one entails another (e.g., arcs individually compose

26 2-paths, which both compose a transitive triad; Figure III). Substantively, this requires the

27 interpretation of configurations as ensembles which collectively drive the formation of a given

28 network. Functionally, this requires the use of higher-order and lower-order configurations in

29 ERGMs in order to have the most holistic understanding of network processes. 
1 To this end, ERGMs are used to simultaneous model the alliance network and one of the co-

2 occurring networks where multiplex triadic dependencies are hypothesised to impact alliance

3 formation (positive nomination, instrumental information exchange) in a pairwise fashion. This

4 results in a total of five different ERGMS - three univariate models for the initial exploration of

5 the distinct, simplex logics of alliance, positive nomination and information exchange, and two

6 bivariate models (alliance-positive nomination, alliance-information exchange) which

7 incorporate those configurations found to be explanatory in univariate analyses. Due to space

8 constraints, univariate models for positive nomination and information exchange are not

9 discussed in the main text. Output for these models may be found in Appendix C. ERGMs are fit

10 using PNet (Wang, Robins \& Pattison, 2008) and XPNet, the bivariate alternative. Note that

11 because these are cross-sectional models, it would be incorrect to say that one type of connection

12 leads to another. In the absence of longitudinal data, it is only appropriate to say that there is an

13 association between the two networks, which are assumed to be in equilibrium, in the manner

14 dictated by the network configuration.

16 As the matrix for co-lobbying is symmetric, associations between this network and alliance is

17 only explored at the dyadic level. This was done as it is not possible to jointly model directed

18 and undirected networks using XPNet. Relatedly, activist dependence is only explored at the

19 dyadic level as it is derived from a weighted symmetric matrix and there is no theoretical

20 impetus for exploration of the larger system that these relations may constitute. In the ERGM

21 specification these two relations are treated as dyadic covariates (see Table I).

\section{5.3.b Specification \& Estimation}

ERGMs for social networks take the following general form:

$$
\operatorname{Pr}(X=x)=\frac{1}{k(\theta)} \exp \left[\sum_{A} \theta_{A} Z_{A}(x)\right]
$$

(i) $\operatorname{Pr}(X=x)$ is the probability of observing the graph that has been measured. 
(ii) $k(\theta)$ is a normalising term which ensures that the equation is a proper probability distribution.

(iii) $A$ indexes a potential network configuration, such as an arc, reciprocated dyad, or transitive triad.

(iv) $\Sigma_{A}$ is the summation over all different configurations in a specific model.

(v) $\theta_{A}$ is the parameter weighting the corresponding configuration $A$.

(vi) $Z_{A}(x)=\prod_{x_{i j} \in A} x_{i j}$ is the general form of a network statistic corresponding to configuration $A$.

(vii) $x$ is a collection of tie variables $\left[x_{i j}\right]$.

Eq. (2) describes a general probability distribution of graphs and is used to determine the particular probability of observing a network. The specific probability of observing any graph $[\operatorname{Pr}(X=x)]$ depends upon both the network statistics $\left[\mathrm{Z}_{A}(x)\right]$ and the non-zero parameters $\left(\theta_{A}\right)$ for all configurations $A$ in the model. For the multivariate case, the network statistic $Z_{A}(x)$ may be a multigraph defined across ties from $M$ networks such that it takes the following general form

$$
\mathrm{Z}_{A}(x)=\sum_{A \in A_{k}} \prod_{(i, j, m) \in A} x_{i j m}
$$

where $A_{k}$ is a collection of isomorphic configurations, $A$, of tie-variables and $x$ is a set of tie variables $\left(x_{i j m}, x \in M\right.$ ) across $M$ networks. For directed networks, $x_{i j m}=1$ if there is a tie from actor $i$ to $j$ in network $m$, otherwise $x_{i j m}=0$.

For a detailed account of ERGM estimation and simulation using (X)PNet see Koskinen and Snijders (2013) and Snijders (2002). Upon convergence, model fit was assessed using the statistics proposed by Robins et al. (2009; note XPnet does not use triad census for bivariate models). For fitted statistics, Goodness of Fit (GoF) $t$-ratios should be less than 0.1 in absolute value, or very nearly so (given the stochastic nature of the goodness of fit process). The model is understood to represent key features of the observed network(s) well if GoF $t$-ratios for statistics proposed by Robins et al. are less than 2.0 in absolute value. GoF $t$-ratios larger than 2.0 are understood as being extreme and the model itself is understood to provide a poor summary of 
1 these statistics. While one does not expect excellent fit on all statistics, this approach is useful as

2 it details exactly what a particular model can and cannot replicate. In respect of this practice and model transparency, those statistics where GoF $t$-ratios are greater than 2.0 are listed with their associated $t$-ratios at the bottom of the table presenting model output under "Extreme Features".

5 The largest absolute value of the GoF $t$-ratios for fitted statistics are also given in the tables presenting output. Complete GoF results for all possible parameters included in XPNet are all available upon request. See Holland and Leinhardt (1970) for triad codes.

Finally, the complicated structure of the models presented here made convergence difficult to obtain, requiring conditioning on the densities (i.e., number of connections) of the observed

11 networks as this improves convergence considerably by limiting the distribution of simulated 12 graphs to those with densities equal to those of the observed networks (see Snijders, Pattison, 13 Robins, \& Handcock, 2006; Snijders \& van Duijin, 2002).

17 6.1. Univariate Analysis of Alliance

The model summarising processes in the alliance network is given in Table III. There are strong positive tendencies for SMOs to reciprocate alliances and for allied SMOs to form dense subregions of the network. This is coupled with a negative tendency for alternating 2-paths outside of those nested in transitive triads, indicating that SMOs tend to form a direct alliance with those whom they indirectly support. Moreover, results indicate that SMOs tend to form alliances with

24 those whom they are structurally equivalent to based on the receipt of alliances from multiple third others (AT-D). This is in conjunction with a tendency against a SMO allying itself with another SMO with whom it establishes alliances with the same third others (AT-U). However, there are positive tendencies for these shared out-ties and shared in-ties - structural holes - to persist outside of closed triads. 


\subsection{Bivariate Analyses}

\section{2.a Bivariate Analysis: Alliance and Positive nomination}

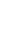

The bivariate model for alliance and positive nomination is presented in Table III. Generally speaking, there were no major changes in the values of the estimates between the bivariate model and the univariate model for alliance. However, the alternating-in-star configuration (A-in-S), used to control from indegree centralisation, does not retain its significance in the bivariate model. Regarding the positive nomination network, specification was altered slightly from the exploratory univariate dimension (Appendix C) for parsimony. Despite being significant, configurations for alternating 2-paths, in-2-stars and out-2-stars were removed. These configurations are nested in the triangle variants that capture the types of closure discussed in Section IV. Their removal enables a simpler model, allowing one to control for triangulation processes distinct to the positive nomination network in order to isolate those operating across layers. As expected given the large number of isolates (16), results indicate the there is a very strong tendency for SMOs to give and receive zero positive nominations. Moreover, when SMOs positively nominate one another it tends to happen only in transitive triads.

Regarding the multivariate parameters, results collectively indicate a significant relationship between the alliance and positive nomination networks, with eight of the twelve bivariate effects being significantly different from zero. At the dyadic level, positive nomination, activist dependence and co-lobbying are all associated with alliance formation. Additionally, there is quite a strong tendency for the exchange of alliance and positive nomination. At the degree level, there are significant associations between the two networks in the form of mixed-2-stars $(B A)$, indicating that organisations who are positively nominated do not tend to form alliances with others. The inverse also applies, i.e., SMO who form alliances with others tend not to be positively nominated. There is no evidence to suggest that positive nomination of others impacts the likelihood that an SMO will receive allies (mixed-2-stars $A B$ ). Finally, three of the higherorder configurations for multiplex triangulation were significant. Results indicate a tendency against the closure of multiple positive nomination 2-paths via an embedded alliance (negative AT-T-BAB). In this scenario, SMOs do not tend to form alliances with those organisations to whom they indirectly express affirmation. This is contrasted with a positive tendency for shared 
1 in-ties from third others (AT-D-BAB) and shared out-ties to multiple third others (AT-U-BAB)

2 to lead to alliance formation. In the first scenario, SMOs tend to ally themselves with those

3 whom they are equivalent to with respect to shared supporters. In the second scenario, SMOs

4 tend to ally themselves with those whom they agree with in their selection of multiple third

5 others for the receipt of affective ties.

6.2.b Bivariate Analysis: Alliance and Information Exchange

8 The multiplex model for alliance and information exchange is also presented in Table III. As the bivariate models are quite large and internally complex, specification played a central role in achieving convergence. Practically, this sometimes meant reducing the number of configurations

11 at the cost of less than satisfactory fit for not explicitly modelled network statistics, thus

12 representing a limitation of the current specification. To achieve convergence, the information

13 exchange component of the bivariate model was simplified whereby only significant effects from

14 the exploratory univariate model (Appendix C) were retained. Transitive closure was also

15 included as it accounts for triangulation, a key process in social systems. Results indicate a very

16 strong and positive tendency for reciprocity. As expected given the zero-order correlation of the

17 in and outdegree distributions $(r=0.82, p=0.00)$, there is a positive tendency for mixed-2-stars.

18 However, there is a negative tendency for multiple 2-paths between SMOs, indicative of a tendency for lower-order 2-paths between organisations.

21 Results of the alliance-information exchange model also indicate that multiplexity plays a

22 significant role in alliance formation. Of the twelve bivariate configurations involving alliance

23 and information exchange, seven were significant. At the dyadic level are significant associations

24 between alliance and activist dependence, co-lobbying and information exchange. Additionally,

25 there is a tendency for the reciprocal exchange of alliance and information. Finally, at the degree

26 level there are also significant associations between the two networks. Results indicate that the

27 same SMOs tend to be information sources and receive allies (positive in-2-star), SMOs that

28 choose others as information sources do not tend to receive allies (negative mixed-2-star AB),

29 and SMOs that are information sources do not tend to form alliances with others (negative

30 mixed-2-star BA). Note that for the negative mixed-2-star effects the inverse also applies, i.e.,

31 SMOs that receive alliances do not tend to select other SMOs in the organisational fields as 
1 information sources (negative mixed-2-star $\mathrm{AB}$ ) and SMOs that ally themselves with others do not tend to be chosen as information sources (negative mixed-2-star BA).

\section{Discussion}

8 Through his analysis of the interplay between familial and organisational ties Gould (1991) clearly demonstrates the importance of the interaction of multiple networks, both emergent and

11 [on mobilisation] cannot even be appreciated without taking multiplexity into account" (Gould, 12 1991, p. 727). While movement scholars have adopted the most general aspect of his argument 13 (i.e., social ties matter), paradoxically, they have ignored the more intriguing foundation upon

14 which it is built - the integral role of multiplexity in the coordination of social movement 15 actors. This has effectively limited theoretical understanding and empirical insight as to the ways 16 in which networks knit a constellation of political actors together for the purpose of social 17 change. This work is to serve as a corrective to that trend. Results confirm the first hypothesis 18 and provide strong support for the second, collectively indicating that multiplexity plays a 19 distinct role in the formation of alliances between SMOs and is a key mechanism in the 20 structuring of social movement organisational fields. I have shown that there are significant 21 associations between alliance and a series of additional networks at the dyadic, degree and triadic

22 levels and these results suggest that scholarship on movement coalitions has failed to give a 23 thorough account of the precise manner in which social ties matter. Furthermore, the complex 24 and intricate nature of these models also suggest that the metaphors widely used in this body of 25 work are poor representations of the network processes within populations of SMOs.

\subsection{Competition and Collaboration: A Note on the Univariate Model for Alliance}

While the crux of this paper is about multiplexity, it is worth setting the stage by commenting on the alliance network itself across the bivariate models. The most striking element of the 
1 univariate alliance dimension of these models is that estimates suggest both competition and collaboration between SMOs. On the one hand, reciprocity and transitive closure configurations work on civic networks has shown to be representative of the integration of the wider organisational field - play very important roles (as indicated by the size of estimates).

5 However, the positive tendency for popularity closure and negative tendency for activity closure suggest a core-periphery structure when interpreted jointly. Estimates for these configurations indicate clustering among SMOs receiving the same organisational allies (positive AT-D)

8 whereas those SMOs that ally themselves with the same multiple third others tend not to form cohesive subgroups (negative AT-U and positive A2P-U). Additionally, results indicate the

10 persistence of structural holes between those SMOs with the same third others as allies (positive

11 A2P-D) over and above the shared in-ties (out-2-stars) nested in closed triangles.

13 Given the persistence of these structural holes, the tendency for popularity closure may seem

14 peculiar. Alliances themselves are a resource, particularly online where the winning of

15 hyperlinks has implications for organisational success by means of increased visibility (Ackland

16 \& O’Neil, 2011), and the boundaries drawn by (not)linking may have direct implications for

17 funding and policy decisions (Young \& Leonardi, 2012). Thus popularity closure may be

18 attributed to a form of competitive embeddedness (Trapido, 2007) ${ }^{19}$ whereby the likelihood of cooperation increases due to competition between two organisations. Premised on there being no a priori reason to expect that the knowledge gained from competition should be less conducive

21 to cooperation than that resulting from non-competitive exchange, the causal logic outlined by

22 Trapido (2007) states that competition fosters awareness and repeated interaction, which breeds

23 familiarity and trust, which, in turn, leads to cooperation. While movement scholarship has

24 advanced contending hypotheses about how competition and collaboration affect alliance

25 formation between SMOs in the face of scarce resources (c.f. McCammon \& Campbell, 2002;

26 Okamoto, 2010), these results indicate that these two processes are not mutually exclusive nor

27 inversely related (as would be evidenced by a negative AT-D estimate) and may operate

28 simultaneously.

\footnotetext{
${ }^{19}$ While Trapido advances this concept within the context of inter-firm competition, insights may prove useful for describing competition and collaboration between organisations, broadly interpreted, over various types of resources.
} 
7.2. Multivariate models of alliance and co-occurring networks

8 Exploration of the embeddedness of alliance directly links this work to a long tradition of research in economic sociology and organisational studies on the embeddedness of action,

10 broadly interpreted, in social structure. In line with this work, expressive ties, represented by

11 positive nomination and activist dependence, were expected to increase the likelihood of alliance

12 formation, understood here to be a form of instrumental exchange (Pilny \& Shumate, 2012).

13 Results indicate that these two expressive relations, in addition to co-lobbying and information

14 exchange, were all entrained. ${ }^{20}$ Moderate to large parameter estimates for these configurations

15 indicate that alliance tends to form alongside other relations, both expressive and instrumental.

17 On the one hand, such a large degree of entrainment suggest that trust, the "open-handed

18 expectations" (Uzzi, 1996; p. 680) bred from establishing new relations alongside existing ties, is

19 a component of alliance formation. Yet these connections are not perfectly beneficial as their

20 formation may incur either internal or external costs. Strategic decision-making is a key aspect of

21 collective action. Relationships represent a means of acquiring resources as organisations invest

22 combinations of social, economic and human capital to build connections from which they may

23 profit (Burt, 1992). Within individual SMOs, the costs and benefits of establishing coalition

24 relations are weighed, and activists generally understand the trade-offs required to maintain

25 aspects of their individual organisation and establish these collaborative ties (Balser, 1997;

26 Staggenborg, 1986). From this perspective, the layering of an alliance on top of additional

27 relations may also be viewed as an attempt by SMOs to better manage these trade-offs by

28 minimising uncertainty and building alliances with those organisations with whom they have

\footnotetext{
20 To assess robustness of dyadic conclusions I also ran a logistic regression quadratic assignment procedure (see Borgatti, Everett \& Johnson, 2013, and Dekker, Krackhardt \& Snijders, 2007). Results (Appendix B) indicate that positive nomination, information exchange and activist dependence are all significantly associated with alliance formation, largely confirming the multiplex dyadic estimates in the bivariate ERGMs.
} 
1 already invested. Indeed, the layering of ties has been empirically shown to reduce uncertainty at the dyadic level in networks of advocacy groups (Heaney, 2014).

4 Despite being beneficial to individual actors, processes at the degree level suggest that such 5 generalised embeddedness may come at a cost to macro-level cohesion. That SMOs who give information (i.e., are followed) and are positively nominated do not tend to ally themselves with others (negative multiplex mixed-2-star BA) indicates the existence of selectivity in the 8 establishment of alliances based on the receipt of relational resources. The alliances explored here are hyperlinks and, similarly to other collective actions, the associational calculus driving

10 their formation may be viewed as a dilemma of costs (Shumate, 2012). Hyperlinking to an

11 organisation contributes both to the collective goals of the hyperlink sender and receiver

12 (collective visibility) and to the individual goals of the receiver by contributing to their

13 individual visibility. Yet receiving hyperlinks yields authority, particularly from the perspective

14 of dominant search engines (Rogers, 2013), and receiving hyperlinks without awarding them to

15 others comes with prestige benefits (Kleinberg, 1999) — both potentially garnering more

16 individual visibility and thus more awareness of a particular SMO's grievances and goals. The

17 notions of prestige and authority can be linked to the commodification of web-native objects

18 such as hyperlinks, hit counters and "social buttons" used to "Like", "Share", "Rate" and

19 generally pass judgement on content. This sees these digital identifiers take on socio-economic

20 value (see Gerlitz and Helmond, 2013). Regarding hyperlinks, prestige and authority are

21 increasingly forfeit the more an actor sends hyperlinks to others. While results pertaining to a

22 lack of indegree centralisation (non-significant A-in-S), a global measure of hierarchy, are

23 consistent with past research concluding that hyperlink networks of SMOs are relatively

24 decentralised (c.f. Ackland \& O’Neil, 2011), degree-based processes do suggest local-level

25 hierarchy whereby some SMOs net allies without going on to associate with other SMOs. ${ }^{21}$

27 The dilemma of visibility associated with local-level hierarchy has been well documented in 28 work on social movement coalitions around the tension between group cohesion and

\footnotetext{
${ }^{21}$ Specifically, the non-significant A-in-S configuration suggests that star-based tie patterns do not drive indegree dispersion. However, given the large tendency for clustering, there still may be actors with high indegrees in the triangulated regions of the network whereby high-indegrees are precisely the result of triangulation. See Lusher and Robins (2013) for a similar interpretation.
} 
1 organisational distinctiveness. Obach (2004, p. 23) labels this tension the "coalition

2 contradiction" whilst Hathaway and Meyer (1993) refer to it as "cooperative differentiation".

3 Regardless, the takeaway is simple - SMOs require some degree of uniqueness to win the

4 resources required to preserve their individual organisations even as distinctiveness weakens

5 their ability to integrate with other organisations and engage in coalition work. Still, there are

6 benefits to be had through cooperation. With the sacrifice of individual visibility and, by

7 extension, resources, social movement organisations may garner legitimacy in new areas, forge

8 useful relations and, through coalitions, reach new audiences (Staggenborg, 2010). Drawing on

9 empirical evidence for large tendencies for reciprocity and transitive closure, previous work on

10 online alliances between non-governmental organisations has concluded that the internal costs of

11 losing individual prestige are outweighed by the external costs of disconnection and the overall

12 benefits of collective visibility (Shumate \& Lipp, 2008). Indeed, these tendencies are also found

13 here. However, the bivariate models suggest that an overly collaborative view of social

14 movement organisational fields may be spurious, at least online.

\section{[Insert Figure IV - Opportunistic Alliance Formation]}

Figure IV | Opportunistic Alliance Formation: Here, organisation $i$ enjoys the resource-related benefits that come with having a platform for grievances (information exchange; purple), the implicit support of others SMOs (activist dependence; green), the legitimacy that comes from collective claims making (co- lobbying; red/dashed), votes of solidarity (positive nomination; blue), and increased prestige (alliance; orange) without establishing an alliance to $k$.

To emphasise this point, consider the following scenario between organisations $i, j, k$ and $h$ and the intricately nested network configurations they are embedded in. Recall that the multiplex mixed-2-star BA estimates indicate that the receipt of some tie $h i$ (positive nomination and/or information exchange) decreases the likelihood of the alliance $i k$. Estimates also indicate a strong

28 tendency for $h i$ to be entrained with alliance, which itself tends to be entrained with activist dependence and co-lobbying. Furthermore, consider the multiplex popularity estimate for alliance and information exchange (in-2-star $\mathrm{AB}$ ) which indicates that $i$ 's selection as an

31 information source by $h$ is associated with the alliance $j i$. Next, consider evidence for the 
1 And, finally, consider related evidence for local-level popularity in the alliance network within 2 triangles (positive shared-out-ties effect), dictating the occurrence of the in-2-star hij. Taken

3 together, these processes suggest that some SMOs pool relational resources, whereby they enjoy

4 the benefits accrued from their structural position in the form of having a platform to share

5 grievances (information exchange) and potentially shape broader movement goals and tactics,

6 the implicit support of other SMOs (activist dependence), the legitimacy that comes from

7 collective claims making (co-lobbying), votes of solidarity (positive nomination), and increased

8 prestige (allies), while choosing not to associate themselves with other organisations via an

9 online alliance (Figure IV).

11 Substantively, this suggests that some SMOs adopt a more opportunistic collaborative strategy

12 whereby organisational maintenance supersedes the pursuit of group cohesion in importance.

13 Given that the organisations studied here are highly professionalised charities, this is somewhat

14 unsurprising as these entities are in direct competition for visibility and the finite financial and

15 social resources it may yield. While it must be said that the magnitude of the multiplex mixed-2-

16 star and in-2-star effects are quite small across both models, these results do lend further support

17 to the simultaneous operation of cooperation and competition and demonstrate that such

18 behaviour may operate both within and across network layers.

20 Arguably, the most convincing evidence for the import of multiplexity in understanding alliance

21 formation is at the triadic level as it is here where the structural context within which alliance is

22 embedded becomes most evident. As Gulati and Gargiulo (1999) argue, the configurations of

23 relations at the triadic level serve as indirect channels of information and a means of assessing

24 reputation and thus provide cues about the appropriateness of some potential organisational

25 partner. Results indicate that these cues also operate via multiplex triangles and provide strong

26 support for the notion of social movement alliances as structurally embedded in multiple network

27 layers.

29 The tendency against alliance formation in the presence of indirect nomination compared with a

30 tendency for alliance formation in the face of agreement on and/or co-citation by third others

31 suggest that mirrored selection is a much more potent signal of the suitability of a potential 
1 alliance partner than indirect nomination. This may be attributed to information on the 2 appropriateness of a potential alliance partner being much more complete in the agreement 3 scenario due to direct confirmation of expressive similarity. A critical component of movement 4 alliances rests with congruence in identity. Imperfect information around identity may be 5 understood to contribute to uncertainty around similarity of values and beliefs. Given that identity may directly influence the patterning of ties in fields of civic organisations (Diani \&

7 Pilati, 2011), identity-based ties may be used to establish boundaries based on collective identity.

8 Furthermore, informational completeness is particularly salient for bureaucratic SMOs, such as

9 those studied here, as these groups typically avoid uncertainty (Morris 1984).

11 Given the extensive operation of multiplexity at the triadic level when alliance is in the presence 12 of positive nomination, the lack of a distinct role for information exchange in multiplex closure 13 was surprising. One explanation may lie with the affective nature of positive nomination, making

14 it more apt in facilitating the formation of cohesive subgroups. Specifically, positive nomination 15 and alliance cluster SMOs together whereas the instrumentality of information exchange and 16 alliance make them apt in the union of clusters of SMOs at the macro-level. The duality of 17 alliance is indicative of its ability to feature collaborative and competitive processes. In the 18 context of previous work on micro-macro integration in civic networks, the operation of positive 19 nomination and information exchange in this manner is perhaps to be expected. However, 20 together the composition of effects across the two bivariate models suggest that the task of 21 micro-macro integration is shared not only across multiples types of co-occurring instrumental 22 and expressive ties but that it is also dispersed across multiple levels of multiplex structure.

\subsection{Generalisability of results and suggestions for future research}

27 Drawing on work on social movements and inter-organisational networks, I have attempted to theoretically and empirically demonstrate the importance of multiplexity in understanding

29 alliance formation in social movement organisational fields. The work here represents an 30 important first exploration of those cross-network processes which give rise to alliance and the 
1 structure of fields of civic organisations more generally. Nevertheless, there are some aspects of

2 this work that deserve mention as they qualify its generalisability.

4 The most obvious of these qualifications lies with the digital nature of the relations analysed

5 here. While few would dispute the existence of some role played by digital media in social movement mobilisation and organisation, it is important to not overly extrapolate from digital trace data. More work must be done around the co-existence and interaction of online and offline relations between SMOs before definitive conclusions about the importance of multiplexity and the operation of the processes I have detailed here can be advanced. Relatedly, I have attempted to extend the notion of coalition relation, specifically alliance, to include hyperlinks. This is not

11 without conceptual caveats. Traditionally, coalition relations are symmetric ties between two

12 SMOs and/or a grouping of multiple SMOs in effort to bring about some change. While results

13 suggest that theories of social movement alliance formation are relevant online, more work is

14 needed on: (a) the degree to which the phenomenology of the establishment of formal alliances

15 coincides with that of hyperlink creation; and (b) the precise manner in which SMOs perceive

16 hyperlinks between themselves and other movement adherents at the organisational level.

18 Another qualification rests with the use of data on the relational patterns of organisational

19 members of a specific issue campaign as opposed to a comprehensive population of SMOs

20 representative of a large-scale movement. This necessitates further exploration of these issues via 21 comparative analyses of the roles of multiplexity in alliance formation between different

22 populations of SMOs across a diverse set of movements.

24 The final qualification rests with the choice of model and specification. While the equilibrium 25 assumption of the cross-sectional exponential random graph model is not wholly unreasonable, a 26 longitudinal model of alliance formation is required to detail causality between co-occurring 27 networks and alliance. Additionally, the ERGMs used here are not social selection models 28 (Robins, Elliott \& Pattison, 2001) in that they only use processes endogenous ${ }^{22}$ to the network to 29 explain its formation as opposed to combining endogenous processes and exogenous predictors

\footnotetext{
${ }^{22}$ Mathematically, the dyadic covariates used here are treated as exogenous predictors in this framework. Here I mean individual attributes of actors and dyads that are not inherently relational.
} 
1 in the form of actor attributes. The assumption of the former scenario is tantamount to a view of

2 all SMOs in this population as homogenous while this latter scenario posits that social actors

3 establish relationships on the basis of certain characteristics they possess. Just as in simplex

4 networks, actor attributes may be expected to play a key role in disentangling the formation of

5 multiplex networks as individual characteristics help shape the embeddedness of actors across

6 relational contexts (Zhao \& Rank, 2013). However, it would be unreasonable to assume

7 spuriousness of the results here in their absence due to the complex, interdependent nature of

8 networks. Regardless, if social space is inherently dynamic and action is embedded in various

9 network locales (Pattison \& Robins, 2000) - comprised of multiple network layers - then it is

10 the simultaneous interaction of structure and attributes that account for emergent processes in a

11 social setting (Robins, Elliott \& Pattison, 2001). It is this dualism in the operation of social

12 phenomena that makes multiplexity indispensable to structural explanations of social movement 13 processes. 


\section{FIGURE I}
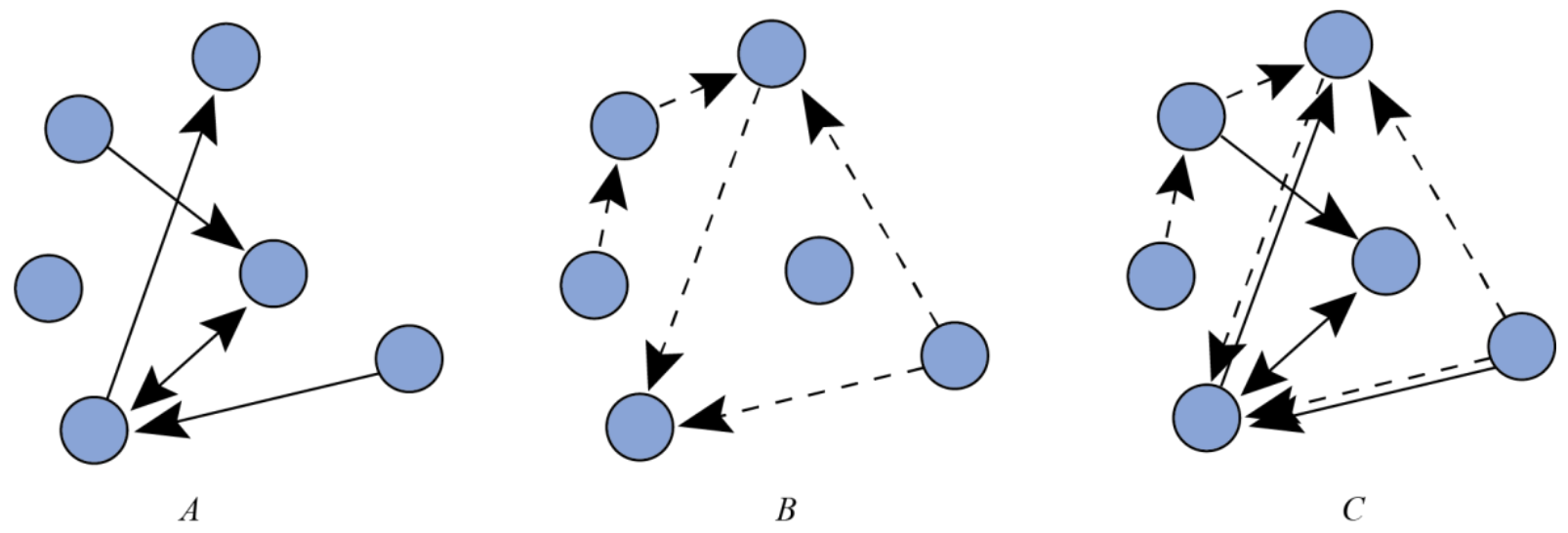


\section{FIGURE II}

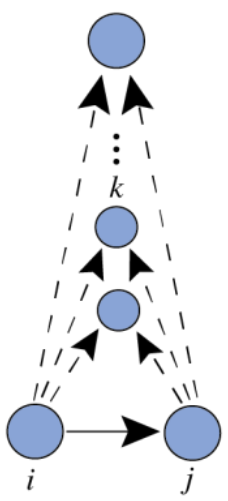

A: Shared out-ties (A2P-U; dashed) with activity closure via alliance (AT-U-BAB; solid).

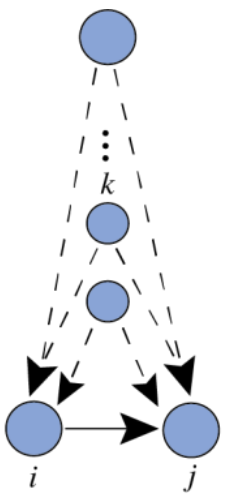

$B$ : Shared in-ties (A2P-D;

dashed) with popularity closure via alliance (AT-D-BAB; solid).
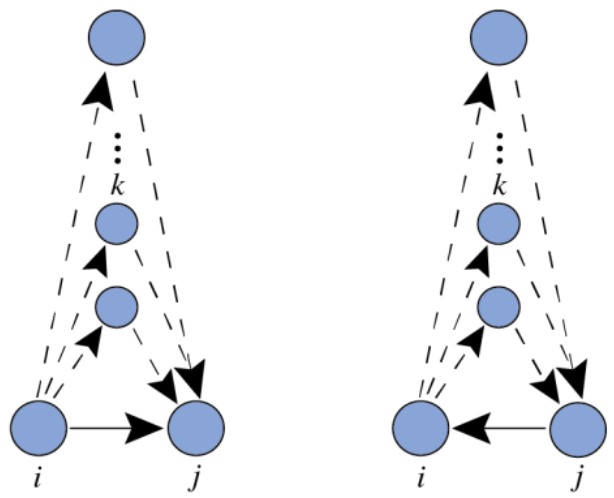

$C$ : Multiple two-paths (A2P-T; dashed) with transitive closure via alliance (AT-T-BAB; solid)
$D$ : Multiple two-paths (A2P-T; dashed) with cyclic closure via alliance (AT-T-BAB; solid). 


\section{FIGURE III}

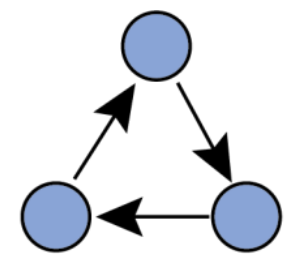

CyclicTriad

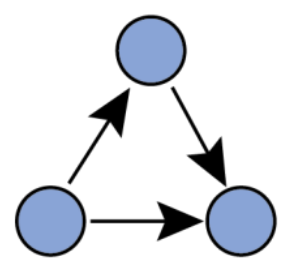

Transitive Triad

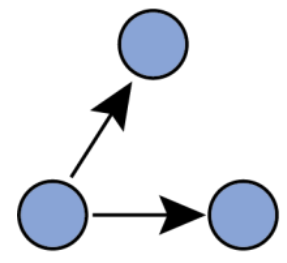

Out-2-Star

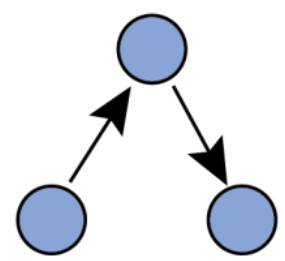

2-Path

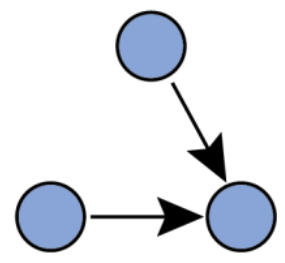

In-2-Star

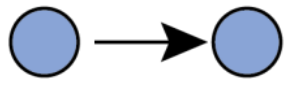

Arc

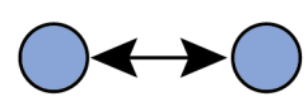

Reciprocity 


\section{FIGURE IV}

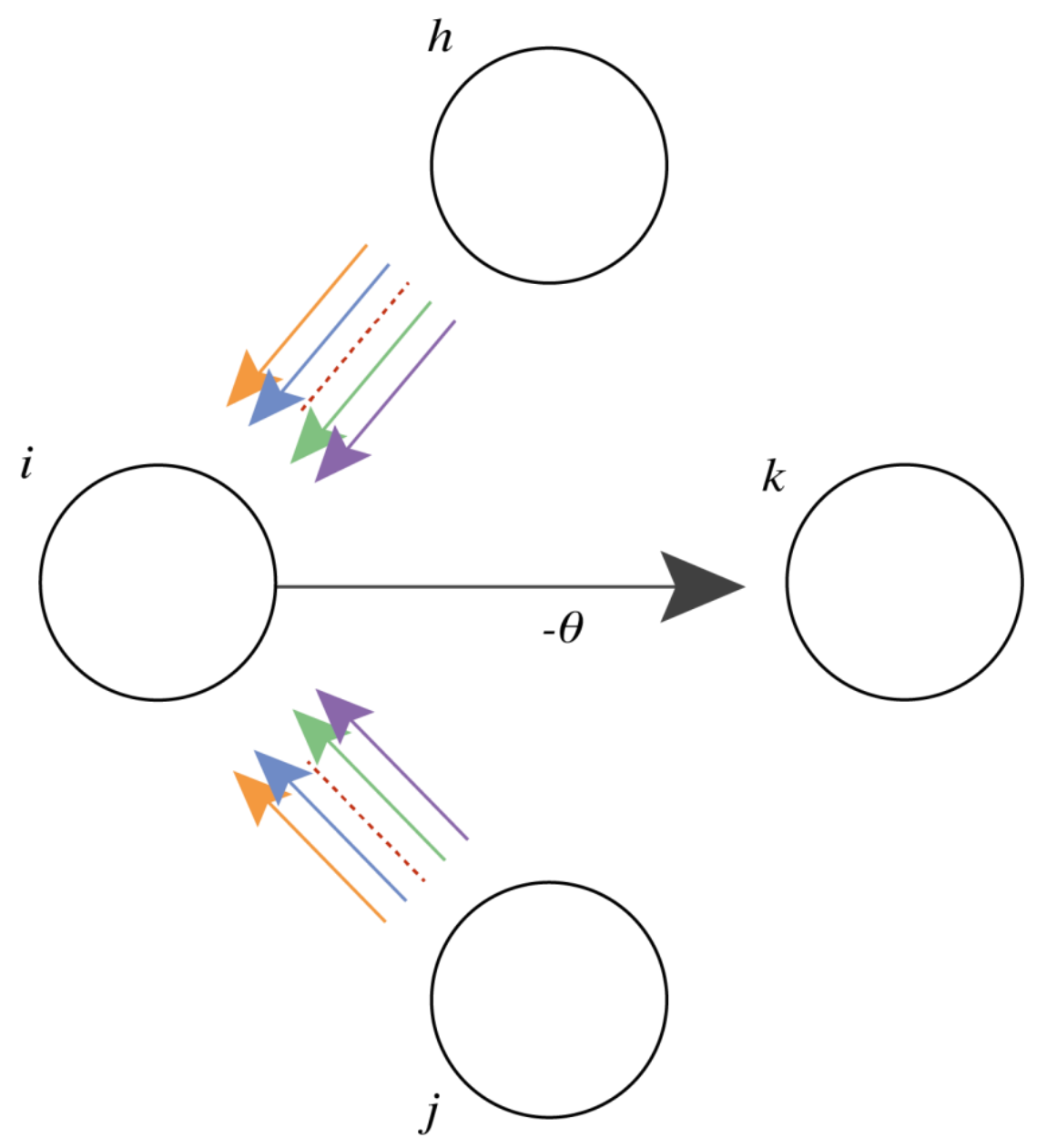


Table II: Descriptive Statistics

\begin{tabular}{|c|c|c|c|c|c|c|c|c|c|c|}
\hline & Type & Online & Weight & Vertices & $\begin{array}{c}\text { Arcs/Edges/ } \\
\text { Non-Null } \\
\text { Dyads }\end{array}$ & $\begin{array}{l}\text { Tie Value } \\
\text { Min/Max }\end{array}$ & Density & $\begin{array}{c}\text { Average } \\
\text { Degree }\end{array}$ & Isolates & $\begin{array}{l}\text { Missing } \\
\text { Vertices }\end{array}$ \\
\hline Alliance & Directed & Yes & Binary & 55 & 382 & - & 0.13 & 6.9 & 3 & 0 \\
\hline $\begin{array}{l}\text { Positive } \\
\text { Nomination }\end{array}$ & Directed & Yes & Binary & 55 & 173 & - & 0.06 & 3.1 & 16 & 2 \\
\hline $\begin{array}{l}\text { Information } \\
\text { Exchange }\end{array}$ & Directed & Yes & Binary & 55 & 1208 & - & 0.41 & 22 & 1 & 1 \\
\hline Co-Lobbying & Undirected & No & Valued & 55 & 34 & $0 / 5$ & 0.02 & 1.2 & 40 & 0 \\
\hline $\begin{array}{l}\text { Activist } \\
\text { Dependence }\end{array}$ & Undirected & Yes & Binary & 55 & 824 & - & 0.28 & 15 & 1 & 1 \\
\hline
\end{tabular}


Table III: Univariate and Bivariate ERGMs * ${ }^{\dagger}$

\begin{tabular}{|c|c|c|c|c|c|c|}
\hline & \multicolumn{2}{|c|}{ Univariate } & \multicolumn{2}{|c|}{ Positive Nomination } & \multicolumn{2}{|c|}{ Information Exchange } \\
\hline & Estimate $(\theta)$ & $\begin{array}{c}\text { Standard } \\
\text { Error (s.e.) }\end{array}$ & $\theta$ & s.e. & $\theta$ & s.e. \\
\hline Alliance (A) & & & & & & \\
\hline Reciprocity & 0.971 & 0.228 & 0.797 & 0.257 & $\mathbf{0 . 8 3 5}$ & 0.255 \\
\hline Sink & 1.347 & 0.717 & 1.404 & 0.706 & 1.087 & 0.723 \\
\hline Indegree Centralisation (A-in-S) & 0.602 & 0.299 & 0.546 & 0.291 & 0.192 & 0.304 \\
\hline Transitive Closure (AT-T) & 1.163 & 0.125 & 1.108 & 0.125 & 1.048 & 0.126 \\
\hline Popularity Closure (AT-D) & 0.185 & 0.092 & 0.280 & 0.100 & 0.318 & 0.094 \\
\hline Activity Closure (AT-U) & -0.255 & 0.091 & -0.352 & 0.091 & -0.277 & 0.073 \\
\hline Alt. 2-Paths $(A 2 P-T)$ & -0.095 & 0.010 & -0.070 & 0.013 & -0.056 & 0.013 \\
\hline Shared In-Ties (A2P-D) & 0.109 & 0.019 & 0.094 & 0.019 & 0.103 & 0.018 \\
\hline Shared Out-Ties $(A 2 P-U)$ & 0.152 & 0.010 & 0.116 & 0.019 & 0.083 & 0.018 \\
\hline \multicolumn{7}{|l|}{ Co-Occurring Network (B) } \\
\hline Reciprocity & - & - & 0.159 & 0.396 & 1.952 & 0.168 \\
\hline Mixed-2-Star & - & - & - & - & 0.075 & 0.004 \\
\hline Isolates & - & - & 2.628 & 0.577 & - & - \\
\hline Transitive Closure (AT-T) & - & - & 1.279 & 0.204 & -0.114 & 0.150 \\
\hline Cyclic Closure (AT-C) & - & - & 0.233 & 0.126 & - & - \\
\hline Popularity Closure (AT-D) & - & - & -0.177 & 0.198 & - & - \\
\hline Activity Closure (AT-U) & - & - & -0.342 & 0.218 & - & - \\
\hline Alt. 2-Paths (A2P-T) & - & - & - & - & -0.046 & 0.019 \\
\hline Shared Out-Ties $(A 2 P-U)$ & - & - & - & - & -0.057 & 0.030 \\
\hline \multicolumn{7}{|l|}{ Bivariate } \\
\hline Dyadic Covariate: A /Activist Dependence & - & - & 0.342 & 0.095 & 0.317 & 0.103 \\
\hline Dyadic Covariate: A/Co-Lobbying & - & - & 0.288 & 0.111 & 0.286 & 0.112 \\
\hline Entrainment $(A r c A B)$ & - & - & 1.348 & 0.227 & 0.886 & 0.189 \\
\hline Exchange (Reciprocity $A B$ ) & - & - & $\mathbf{0 . 8 3 2}$ & 0.236 & 0.678 & 0.191 \\
\hline Popularity (In-2-Star AB) & - & - & 0.027 & 0.016 & 0.077 & 0.009 \\
\hline Activity (Out-2-Star AB) & - & - & -0.017 & 0.012 & 0.004 & 0.010 \\
\hline Mixed-2-Star $A B$ & - & - & 0.009 & 0.015 & -0.076 & 0.010 \\
\hline Mixed-2-Star BA & - & - & -0.029 & 0.014 & -0.041 & 0.010 \\
\hline Multiplex Transitive Closure (AT-T-BAB) & - & - & -0.524 & 0.123 & 0.624 & 0.338 \\
\hline Multiplex Cyclic Closure (AT-C-BAB) & - & - & -0.194 & 0.130 & 0.243 & 0.322 \\
\hline Multiplex Popularity Closure (AT-D-BAB) & - & - & 0.218 & 0.071 & -0.354 & 0.291 \\
\hline Multiplex Activity Closure (AT-U-BAB) & - & - & 0.226 & 0.084 & -0.502 & 0.323 \\
\hline
\end{tabular}

BOLD indicates a significant estimate, i.e., the ratio of $\theta$ to the s.e. $\theta$ is greater than two

$\uparrow$ The absolute value of convergence $t-$ ratios for all parameters in all models are less than 0.1 , the requirement for convergence (see Koskin \& Snijders, 2013).

Largest GoF t-Ratio: 0.02

Extreme Features: Triads-021C (-2.203), $030 T$ (2.686)
Largest GoF t-Ratio: 0.09

Extreme Features: -
Largest GoF t-Ratio: 0.11

Extreme Features: 3-Out-Star B (2.049); AKT-C B (-3.604) 


\section{APPENDIX A - List of Organisations in the Hardest Hit Campaign}

Action for Blind People

Action for Myalgic Encephalomyelitis (M.E.)

Action on Hearing Loss/Royal National Institute For Deaf People

Age UK

Ambitious About Autism

Arthritis Care

Breast Cancer Care

British Lung Foundation

Cancer and Leukaemia in Childhood (CLIC) Sargent

Carers UK

Child Poverty Action Group (CPAG)

Citizens Advice Bureaux

Crohn's and Colitis UK (NACC)

Cystic Fibrosis Trust

Deafblind UK

Disability Rights UK

Drugscope

Every Disabled Child Matters

Haemophilia Society

Hafal

Inclusion London

Learning Disability Coalition

Leonard Cheshire Disability

Livability

London Advice Services Alliance (LASA)

Macmillan Cancer Support

Mencap

Meningitis Research Foundation

Mind (The National Association For Mental Health)

Motor Neurone Disease (MND) Association

Multiple Sclerosis (MS) Society

Muscular Dystrophy Campaign

National AIDS Trust

National Autistic Society (NAS)

National Deaf Children's Society (NDCS)

National Rheumatoid Arthritis Society (NRAS)

National Union of Students

Parkinson's UK

Repetitive Strain Injury (RSI) Action (RSIA)

Rethink Mental Illness

Royal College of Psychiatrists

Royal National Institute of Blind People (RNIB)

Scope

Scottish Association for Mental Health

Sense: The UK Deafblind Charity

Sue Ryder

The Guide Dogs For The Blind Association

The Papworth Trust

The Stroke Association

The Trades Union Congress (TUC)

The UK Disabled People's Council (UKDPC)

Transport for All

United Response

Vitalise

Welsh Association of ME \& CFS Support (WAMES) https://www.actionforblindpeople.org.uk/

http://www.afme.org.uk/

http://www.actiononhearingloss.org.uk/

http://www.ageuk.org.uk/

http://www.ambitiousaboutautism.org.uk/

http://www.arthritiscare.org.uk/

http://www.breastcancercare.org.uk/

http://www.blf.org.uk/

http://www.clicsargent.org.uk/

http://www.carersuk.org/

http://www.cpag.org.uk/

http://www.citizensadvice.org.uk/

http://www.crohnsandcolitis.org.uk/

https://www.cysticfibrosis.org.uk/

http://www.deafblind.org.uk/

http://www.disabilityrightsuk.org/

http://www.drugscope.org.uk/

http://www.edcm.org.uk/

http://www.haemophilia.org.uk/

http://www.hafal.org/

http://www.inclusionlondon.co.uk/

http://www.learningdisabilitycoalition.org.uk/

http://www.lcdisability.org/

http://www.livability.org.uk/

http://www.lasa.org.uk/

http://www.macmillan.org.uk/

http://www.mencap.org.uk/

http://www.meningitis.org/

http://www.mind.org.uk/

http://www.mndassociation.org/

http://www.mssociety.org.uk/

http://www.muscular-dystrophy.org/

http://www.nat.org.uk/

http://www.autism.org.uk/

http://www.ndcs.org.uk/

http://www.nras.org.uk/

http://www.nus.org.uk/

http://www.parkinsons.org.uk/

http://www.rsiaction.org.uk/

http://www.rethink.org/

http://www.rcpsych.ac.uk/

http://www.rnib.org.uk/

http://www.scope.org.uk/

http://www.samh.org.uk/

http://www.sense.org.uk/

http://www.sueryder.org/

http://www.guidedogs.org.uk/

http://www.papworth.org.uk/

http://www.stroke.org.uk/

http://www.tuc.org.uk/

http://www.ukdpc.net/

http://www.transportforall.org.uk/

http://www.unitedresponse.org.uk/

http://www.vitalise.org.uk/

http://www.wames.org.uk/ 


\section{B - Logistic Regression Quadratic Assignment Procedure}

Logistic Regression Quadratic Assignment Procedure (LR-QAP)

\begin{tabular}{|c|c|c|c|c|}
\hline & Coefficient & Odds Ratio & t-statistic & P-Value \\
\hline \multicolumn{5}{|l|}{ Parameters } \\
\hline Intercept & -3.124 & 0.044 & -25.495 & - \\
\hline Positive Nomination & $1.241 * * *$ & 3.459 & 7.178 & 0.000 \\
\hline Information Exchange & $1.528 * * *$ & 4.611 & 11.611 & 0.000 \\
\hline Activist Dependence & $0.422 * *$ & 1.526 & 3.594 & 0.026 \\
\hline Co-Lobbying & 0.254 & 1.290 & 1.592 & 0.128 \\
\hline \multicolumn{5}{|l|}{$n=2970$} \\
\hline \multicolumn{5}{|l|}{ Permutations: 10,000} \\
\hline Model P-Value: 0.000 & & & \multirow{2}{*}{\multicolumn{2}{|c|}{$\begin{array}{l}\text { *** Significant at the } 99 \% \text { Confidence Level } \\
\text { ** Significant at the } 95 \% \text { Confidence Level }\end{array}$}} \\
\hline$R$-Squared: 0.115 & & & & \\
\hline
\end{tabular}

\section{C - Univariate Models For Positive Nomination and Information Exchange}

Table IV: Univariate and Bivariate ERGMs $* \dagger$

\begin{tabular}{|c|c|c|c|c|}
\hline \multirow[b]{3}{*}{ Reciprocity } & \multicolumn{2}{|c|}{ Positive Nomination } & \multicolumn{2}{|c|}{ Information Exchange } \\
\hline & Estimate $(\theta)$ & Standard Error (s.e.) & $\theta$ & s.e. \\
\hline & 0.497 & 0.369 & 2.037 & 0.155 \\
\hline Mixed-2-Star & - & - & 0.075 & 0.004 \\
\hline Isolates & 2.641 & 0.552 & - & - \\
\hline Transitive Closure (AT-T) & 1.279 & 0.194 & 0.432 & 0.317 \\
\hline Cyclic Closure (AT-C) & 0.115 & 0.123 & -0.129 & 0.285 \\
\hline Popularity Closure (AT-D) & -0.173 & 0.191 & -0.182 & 0.303 \\
\hline Activity Closure (AT-U) & -0.233 & 0.200 & -0.258 & 0.295 \\
\hline Alt. 2-Paths (A2P-T) & -0.110 & 0.034 & -0.214 & 0.073 \\
\hline Shared In-Ties $(A 2 P-D)$ & 0.116 & 0.018 & 0.147 & 0.074 \\
\hline Shared Out-Ties $(A 2 P-U)$ & 0.114 & 0.046 & 0.158 & 0.074 \\
\hline $\begin{array}{l}\text { * BOLD indicates a significant } \\
\text { estimate, i.e., the ratio of } \theta \text { to } \\
\text { the s.e. } \theta \text { is greater than two }\end{array}$ & \multicolumn{2}{|c|}{ Largest GoF t-Ratio: 0.04} & \multicolumn{2}{|c|}{ Largest GoF t-Ratio: 0.06} \\
\hline $\begin{array}{l}\text { The absolute value of } \\
\text { convergence t-ratios for all } \\
\text { parameters in all models are } \\
\text { less than 0.1, the requirement } \\
\text { for convergence (see Koskin } \\
\text { \& Snijders, 2013). }\end{array}$ & \multicolumn{2}{|c|}{ Extreme Features: Triad 030T(2.005) } & \multicolumn{2}{|c|}{$\begin{array}{c}\text { Extreme Features: } \\
\text { Isolates (2.633); 2-in-Stars (2.046); 3-in-stars } \\
\text { (3.048); Indegree Dist. Skew (2.397); Corr. Coef. } \\
\text { In/Outdegree Dist. (-13.612); Global Clustering } \\
\text { Ctm (2.241); Triads - 120C (-3.538), 120D } \\
\text { (5.477), 120U (3.459),030C (-3.736), 021C } \\
\text { (-2.335), 021U (2.402) }\end{array}$} \\
\hline
\end{tabular}




\section{D - Some Additional Notes on Hyperlinking As An Associational Practice}

There have been a number of academic conversations about the nature of hyperlinks and the degree to which they are useful as a tool for sociological inquiry. One of the most visible issues is the degree to which hyperlinking is competitive or antagonistic in nature. As with all research, some assumptions have to be made. I have based my interpretation of hyperlinking as collaborative versus hostile largely on the context - relations amongst members of an aggrieved population of professional SMOs with broadly aligned goals. Alternatively, consider the case of tabloid and celebrity gossip websites where one may expect to see both positive and negative commentary on individuals and events. In this scenario an assumption of representational communication is much less robust given the sarcastic and sardonic nature of these digital spaces. When ascribing meaning to hyperlinks found in this corner of the Web there is a reasonable expectation that connections are not affirmative, instead potentially being used to connect readers to content, individuals or organisations that are being ridiculed or criticised. In the case of strategic organisational actors, such as set of NGOs or government agencies, collaborative hyperlinking is a much more reasonable assumption. For a further discussion see Rogers (2013) on the online politics of association. 


\section{Bibliography}

Ackland, R. (2013). Web Social Science: Concepts, Data and Tools for Social Scientists in the Digital Age. Sage

Ackland, R., \& O’Neil, M. (2011). Online collective identity: The case of the environmental movement. Social Networks, 33(3), 177-190.

Andrews, K. \& Edwards, B. (2004). Advocacy organizations in the U.S. political process. Annual Review of Sociology 30, 479-506.

Arnold, G. (2011). The impact of social ties on coalition strength and effectiveness: The case of the battered women's movement in St Louis. Social Movement Studies, 10(02), 131-150.

Baldassarri, D., \& Diani, M. (2007). The integrative power of civic networks. American Journal of Sociology, 113(3), 735-780.

Balser, D. B. (1997). The impact of environmental factors on factionalism and schism in social movement organizations. Social Forces, 76, 199-228.

Benford, R. D., \& Snow, D. A. (2000). Framing processes and social movements: An overview and assessment. Annual Review of Sociology, 26(1), 611-639.

Bennett, W. L., Segerberg, A., \& Walker, S. (2014). Organization in the crowd: peer production in large-scale networked protests. Information, Communication \& Society, 17(2), 232-260.

Blau, P. M. (1964). Exchange and power in social life. Transaction Publishers.

Borgatti, S. P., Everett, M. G., \& Johnson, J. C. (2013). Analyzing Social Networks. SAGE.

Brandes, U. (2008). On variants of shortest-path betweenness centrality and their generic computation. Social Networks, 30(2), 136-145.

Breiger, R. L. (1974). The duality of persons and groups. Social forces, 53(2), 181-190.

Broder, A., Kumar, R., Maghoul, F., Raghavan, P., Rajagopalan, S., Stata, R., Tomkins, A., \& Wiener, J. (2000). Graph structure in the web. Computer networks, 33(1), 309320.

Brown, P., \& Zavestoski, S. (2004). Social movements in health: An introduction. Sociology of Health \& Illness, 26(6), 679-694.

Burt, R. S. (1992). Structural holes: The social structure of competition. Harvard University Press. 
Bystydzienski, J. M., \& Schacht, S. P. (Eds.). (2001). Forging radical alliances across

difference: Coalition politics for the new millennium. Rowman \& Littlefield.

Calhoun, C. (2013). Occupy Wall Street in perspective. The British Journal of Sociology, 64(1), 26-38.

Cammaerts, B. (2012). Protest logics and the mediation opportunity structure. European Journal of Communication, 27(2), 117-134.

Cardillo, A., Gómez-Gardeñes, J., Zanin, M., Romance, M., Papo, D., del Pozo, F., \& Boccaletti, S. (2013). Emergence of network features from multiplexity. Scientific reports, 3 , Article 1344.

Císař, O. (2013). Interest groups and social movements. In The Encyclopaedia of Social and Political Movements. (Vol. 2, p. 616-620). Blackwell.

Cornfield, D. B. \& McCammon, H. J. (2010). Approaching mergers: The converging public policy agendas of the AFL and CIO, 1938-1955. In N. van Dyke \& H. J. McCammon (Eds.), Strategic alliance: Coalition building and social movements. University of Minnesota Press.

Croteau, D. \& Hicks, L. (2003). Coalition framing and the challenge of a consonant frame pyramid: The case of a collaborative response to homelessness. Social Problems, $50,251-272$.

De Domenico, M., Solé-Ribalta, A., Cozzo, E., Kivelä, M., Moreno, Y., Porter, M. A., Gómez S., \& Arenas, A. (2013). Mathematical Formulation of Multilayer Networks. Physical Review X, 3(4), 041022.

Dekker, D., Krackhardt, D., \& Snijders, T. A. (2007). Sensitivity of MRQAP tests to collinearity and autocorrelation conditions. Psychometrika, 72(4), 563-581.

Diani, M. (1992). The concept of social movement, Sociological Review, 40(1), 1-25.

Diani, M. (2000). Social movement networks virtual and real. Information, Communication \& Society, 3(3), 386-401.

Diani, M. (2003). Networks and social Movements: A research programme. In M. Diani \& D. McAdam (Eds), Social movements and networks: Relational approaches to collective action. Oxford University Press. 
Diani, M. (2013). Organizational fields and social movement dynamics. In J. van Stekelenburg, C. Roggeband, \& B. Klandermans (Eds.), The future of social movement research: Dynamics, mechanisms and processes. University of Minnesota Press.

Diani, M. (Forthcoming). The cement of civil society: Studying networks in localities. Cambridge University Press.

Diani, M., \& McAdam, D. (Eds.). (2003). Social movements and networks: Relational approaches to collective action. Oxford University Press.

Diani, M., \& Pilati, K. (2013). Interests, identities, and relations: Drawing boundaries in civic organisational fields. Mobilization: An International Journal, 16(3), 265-282.

DiMaggio, P. J \& Powell, W. W. (1983). The iron cage revisited: Institutional isomorpohism and collective rationality in organizational fields. American Sociological Review, $48,147-60$.

Dysart, J. (2002). Making the most of promotional links. Public Relations Tactics, 9(11), 21.

Ferree, M. M., \& Roth, S. (1998). Gender, class and the interaction between social movements: A strike of West Berlin day care workers. Gender \& Society, 12(6), 626-648.

Ferriani, S., Fonti, F., \& Corrado, R. (2013). The social and economic bases of network multiplexity: Exploring the emergence of multiplex ties. Strategic Organization, 11(1), 7-34.

Gaby, S., \& Caren, N. (2012). Occupy online: How cute old men and Malcolm X recruited 400,000 US users to OWS on Facebook. Social Movement Studies, 11(3-4), 367374.

Garrido, M. \& Halavais, A. (2003). Mapping networks of support for the Zapatista Movement: Applying social-network analysis to study contemporary social movements. In M. McCaughey \& M. Ayers (Eds.), Cyberactivism: Online activism in theory and practice (pp. 165-184). Taylor \& Francis.

Garrett, R. K. (2006). Protest in an Information Society: A review of literature on social movements and new ICTs. Information, Communication and Society, 9(2), 202224.

Gerlitz, C., \& Helmond, A. (2013). The like economy: Social buttons and the data-intensive web. New Media \& Society, 15(8), 1348-1365. 
Gonzalez-Bailon, S. (2007). Mapping civil society on the Web: Networks, alliances, and informational landscapes. Unpublished PhD Thesis. The University of Oxford (Nuffield College)

Gonzalez-Bailon, S., Borge-Holthoefer, J., Rivero, A., \& Moreno, Y. (2011). The dynamics of protest recruitment through an online network. Scientific Reports, 1, Article 197.

Gould, R. V. (1991). Multiple networks and mobilization in the Paris Commune, 1871. American Sociological Review, 56(6), 716-729.

Grossman, Z. (2001). Let's not create evilness for this river: Interethnic environmental alliances of Native Americans and rural whites in Northern Wisconsin. In J. M. Bystydzienski, S. P. Schacht (Eds.), Forging alliances across difference: Coalition politics for the new millennium (p. 146-159). Rowman and Littlefield. Granovetter, M. (1973). The strength of weak ties. American Journal of Sociology, 78(6). 13601380.

Granovetter, M. (1985). Economic action and social structure: The problem of embeddedness. American Journal of Sociology, 91(3) 481-510.

Gluckman, M. (1962). Les Rites de Passage. In M. Gluckman (Ed.), Essays on the ritual of social relations. Manchester University Press.

Gómez-Gardenes, J., Reinares, I., Arenas, A., \& Floría, L. M. (2012). Evolution of cooperation in multiplex networks. Scientific reports, 2, Article 620.

Gulati, R. (1995). Social structure and alliance formation patterns: A longitudinal analysis. Administrative Science Quarterly, 40(4), 619-652.

Gulati, R. \& Gargiulo, M. (1999). Where do interorganizational networks come from? American Journal of Sociology 104(5), 1439-93.

Harlow, S. (2012). Social media and social movements: Facebook and an online Guatemalan justice movement that moved offline. New Media \& Society, 14(2), 225-243.

Hathaway, W., \& Meyer, D. S. (1993). Competition and cooperation in social movement coalitions: Lobbying for peace in the 1980s. Berkeley Journal of Sociology, 157183.

Heaney, M. T. (2014). Multiplex networks and interest group influence reputation: An exponential random graph model. Social Networks, 36, 66-81.

Homans, G. C. (1950). The human group. Harcourt Brace. 
Homans, G. C. (1974). Social behaviour: Its elementary forms. Harcourt Brace.

Holland, P.W., \& Leinhardt, S. (1970). A method for detecting structure in sociometric data. American Journal of Sociology 70, 492-513.

Huisman, M. (2009). Imputation of missing network data: some simple procedures. Journal of Social Structure, 10(1), 1-29.

Huitsing, G., Van Duijn, M. A. J., Snijders, T. A. B., Wang, P., Sainio, M., Salmivalli, C., \& Veenstra, R. (2012). Univariate and multivariate models of positive and negative networks: Liking, disliking, and bully-victim relationships. Social Networks, $34(4), 645-657$.

Jenkins, J. C. (1998). Channeling social protest: Foundation patronage of contemporary social movements. Private action and the public good, 206-216.

Jenkins, J. C. (1983). Resource Mobilization Theory and the study of social movements. Annual Review of Sociology, 9, 527-53.

Kadivar, M. A. (2013). Alliances and perception profiles in the Iranian Reform Movement, 1997 to 2005. American Sociological Review, 78(6), 1063-1086.

Kapferer, B. (1969). Norms and the manipulation of relationships in a work context. In J. C. Mitchell (Dd.), Social networks in urban situations. Manchester University Press.

Katz, H., \& Anheier, H. (2006). Global connectedness: The structure of transnational NGO networks. In M. Glasius, M. Kaldor, \& H. Anheir (Eds.), Global Civil Society. SAGE.

Kenis, P. \& Knoke, D. (2002). How organizational field networks shape inter-organizational tieformation rates. Academy of Management Review, 27(2), 275-293.

Kivelä, M., Arenas, A., Barthelemy, M., Gleeson, J. P., Moreno, Y., \& Porter, M. A. (2013). Multilayer networks. arXiv preprint, 1309.7233.

Kleinberg, J. (1999). Authoritative sources in a hyperlinked environment. Journal of the ACM, 46(5), 604-632.

Kleinberg, J. \& S. Lawrence. The Structure of the Web. Science, 294(2001), 1849.

Koskinen, J. H., Robins, G. L., Wang, P., \& Pattison, P. E. (2013). Bayesian analysis for partially observed network data, missing ties, attributes and actors. Social Networks, 35(4), 514-527. 
Koskinen, J. \& Snijders, T. (2013). Simulation, Estimation, and Goodness of Fit. In D. Lusher, J. Koskinen \& G. Robins (Eds.), Exponential Random Graph Models for social networks: Theory, methods and applications. Cambridge University Press.

Kriesi, H. (2004). Political context and opportunity. In D. A. Snow, S. A. Soule \& H. Kriesi, H. (Eds.), The Blackwell companion to social movements. Blackwell.

Kwak, H., Lee, C. Park, H., \& Moon, S. (2010, April). What is Twitter, a social network or news media? Proceedings of the 19th International World Wide Web (WWW) Conference, Raleigh, North Carolina.

Laumann, E. O., Galaskiewicz, J. \& Marsden, P. (1978). Community structure as interorganizational linkages. Annual Review of Sociology 4, 455-84.

Lazega, E., \& Pattison, P. E. (1999). Multiplexity, generalized exchange and cooperation in organizations: A case study. Social networks, 21(1), 67-90.

Lee, S., \& Monge, P. (2011). The coevolution of multiplex communication networks in organizational communities. Journal of Communication, 61(4), 758-779.

Lomi, A., \& Pattison, P. (2006). Manufacturing relations: An empirical study of the organization of production across multiple networks. Organization Science, 17(3), 313 - 332

Lomi, A. \& Pallotti, F. (2013). How to close a hole: Exploring alternative closure mechanisms in interorganizational networks. In D. Lusher, J. Koskinen \& G. Robins (Eds.), Exponential Random Graph Models for social networks: Theory, methods and applications. Cambridge University Press

Lusher, D., \& Ackland, R. (2011). A relational hyperlink analysis of an online social movement. Journal of Social Structure, 12(5)

Lusher, D. \& Robins, G. (2013). Personal attitudes, perceived attitudes and social structures: A social selection model. In D. Lusher, J. Koskinen \& G. Robins (Eds.), Exponential Random Graph Models for social networks: Theory, methods and applications. Cambridge University Press.

Mansell, R. (2012). Imagining the Internet: Communication, innovation, and governance. Oxford University Press.

Marwick, A. E., \& boyd, D. (2010). I tweet honestly, I tweet passionately: Twitter users, context collapse, and the imagined audience. New Media \& Society, 13(1), 114-133. 
McAdam, D., \& Paulsen, R. (1993). Specifying the relationship between social ties and activism. American Journal of Sociology, 99(3), 640-667.

McCammon, H. J. \& Campbell, K. E. (2002). Allies on the road to victory: Coalition formation between the Suffragists and the Woman's Christian Temperance Union.

Mobilization: An International Journal, 7, 231-251.

McCarthy, J. D., \& Zald, M. N. (1977). Resource mobilization and social movements: A partial theory. American Journal of Sociology, 82, 1212-41.

Meyer, D. S., \& Whittier, N. (1994). Social movement spillover. Social Problems, 41, $277-91$.

Meyer, D. S., \& Corrigall-Brown, C. (2005). Coalitions and political context: U.S. movements against wars in Iraq. Mobilization: An International Journal, 10(3), 327-346.

Minkoff, D. \& McCarthy, J. D. (2005). Reinvigorating the study of organizational processes in social movements. Mobilization: An International Journal, 10, 298-308.

Mische, A. (2008). Partisan publics: Communication and contention across Brazilian youth activist networks. Princeton University Press.

Monge, P. R. \& Contractor, N. S. (2003). Theories of communication networks. Oxford University Press.

Morris, A. D. (1984) The origins of the Civil Rights Movement: Black communities organizing for change. Free Press.

Morozov, E. (2011). The net delusion: The dark side of Internet freedom. PublicAffairs.

Obach, B. K. (Ed.). (2004). Labor and the environmental movement: The quest for common ground. MIT Press.

Okamoto, D. A. (2010). Organizing across ethnic boundaries in the past-civil rights era: Asian american panethnic coalition. In N. van Dyke \& H. J. McCammon (Eds.), Strategic alliance: Coalition building and social movements. University of Minnesota Press.

Osa, M. (2003) Networks in opposition: Linking organizations through activists in the Polish People's Republic. In M. Diani \& D. McAdam (Eds.), Social movements and networks: Relational approaches to collective action (p. 77-104). Oxford University Press. 
Park, H. S. (2008). Forming coalitions: A network-theoretic approach to the contemporary South Korean environmental movement. Mobilization: An International Quarterly, 13(1), 99-114.

Park, H. W. (2002). Examining the determinants of who is hyperlinked to whom: A survey of Webmasters in Korea. First Monday, 7(11).

Park, H.W., Kim, C.S. \& Barnett, G.A. (2004). Socicommunicational structure among political actors on the web in south korea: the dynamics of digital presence in cyberspace. New Media \& Society 6(3), 403-423.

Pattison, P., \& Robins, G. (2002). Neighborhood-based models for social networks. Sociological Methodology, 32(1), 301-337.

Pearlman L. (2009). I like this. The Facebook Blog, 10 February. Available at: http://blog.facebook.com/blog.php?post=53024537130 (accessed 23 October 2014).

Pilny, A. \& Shumate, M. (2012). Hyperlinks as extensions of offline instrumental collective action. Information, Communication \& Society, 15(2), 260-286.

Pitt, L., van der Merwe, R., Berthon, P., Salehi-Sangari, E. \& Caruana, A. (2006). Global alliance networks: A comparison of biotech SMEs in Sweden and Australia. Industrial Marketing Management, 35(5), 600-610.

Rank, O. N., Robins, G. L., \& Pattison, P. E. (2010). Structural logic of intraorganizational networks. Organization Science, 21(3), 745-764.

Rivera, M. T., Soderstrom, S. B., \& Uzzi, B. (2010). Dynamics of dyads in social networks: Assortative, relational, and proximity mechanisms. Annual Review of Sociology, $36,91-115$.

Robins, G., Elliott, P., \& Pattison, P. (2001). Network models for social selection processes. Social networks, 23(1), 1-30.

Robins, G., Pattison, P., \& Wang, P. (2009). Closure, connectivity and degree distributions: Exponential random graph $\left(\mathrm{p}^{*}\right)$ models for directed social networks. Social Networks, 31(2), 105-117.

Rogers, R. (2013). Digital methods. MIT Press. 
Rogers, R. \& Marres, N. (2000). Landscaping climate change: A mapping technique for understanding science and technology debates on the world wide web. Public Understanding of Science, 9(2), 141-163

Rose, F. (2000). Coalitions across the class divide: Lessons from the labor, peace, and environmental movements. Cornell University Press.

Rucht, D. (2004). Movement allies, adversaries, and third parties. In D. A. Snow, S. A. Soule \& H. Kriesi, H. (Eds.), The Blackwell companion to social movements. Blackwell.

Shalizi, C. R., \& Rinaldo, A. (2013). Consistency under sampling of exponential random graph models. The Annals of Statistics, 41(2), 508-535.

Shipilov, A. V. \& Li, S. X. (2012) The missing link: The effect of customers on the formation of relationships among producers in the multiplex triads. Organization Science 23(2), 472-91.

Shumate, M. (2012). The evolution of the HIV/AIDS NGO hyperlink network. Journal of Computer-Mediated Communication, 17, 120-134.

Shumate, M., \& Dewitt, L. (2008). The North/South divide in NGO hyperlink networks. Journal of Computer-Mediated Communication, 13(2), 405-428.

Shumate, M. \& Lipp, J. (2008). Connective collective action online: An examination of the hyperlink network structure of an NGO issue network. Journal of Computer Mediated Communication, 14, 178-201.

Snijders, T. A. B., 2002. Markov chain monte carlo estimation of exponential random graph models. Journal of Social Structure 3, 1-41.

Snijders, T. A. B, \& Van Duijn, M. A. (2002). Conditional maximum likelihood estimation under various specifications of exponential random graph models. Contributions to social network analysis, information theory, and other topics in statistics, 117134.

Snijders, T. A. B., Pattison, P. E., Robins, G. L., \& Handcock, M. S. (2006). New specifications for exponential random graph models. Sociological methodology, 36(1), 99-153.

Staggenborg, S. (1986). Coalition work in the pro-choice Movement: Organizational and environmental opportunities and obstacles. Social Problems, 33, 374-390. 
Staggenborg, S. (2010). Conclusion. In N. van Dyke \& H. J. McCammon (Eds.), Strategic alliance: Coalition building and social movements. University of Minnesota Press.

Szell, M., Lambiotte, R., \& Thurner, S. (2010). Multirelational organization of large-scale social networks in an online world. Proceedings of the National Academy of Sciences, 107(31), 13636-13641.

Tarrow, S. (2005). The new transnational activism: Social movements and contentious politics. Cambridge University Press.

Tattersall, A. (2010). Power in coalition: Strategies for strong unions and social change. Cornell University Press.

Theocharis, Y. (2013). The wealth of (occupation) networks? Communication patterns and information distribution in a Twitter protest network. Journal of Information Technology \& Politics, 10(1), 35-56.

Trapido, D. (2007). Competitive embeddedness and the emergence of interfirm cooperation. Social Forces, 86(1), 165-191.

Tremayne, M. (2014). Anatomy of protest in the digital era: A network analysis of Twitter and Occupy Wall Street. Social Movement Studies, 13(1), 110-126.

Tremayne, M. (2004). The web of context: Applying network theory to the use of hyperlinks in journalism on the web. Journalism \& Mass Communication Quarterly, 81, 237253.

Umphress, E. E., Labianca, G., Brass D. J., Kass, E., \& Scholten, L. (2003). The role of instrumental and expressive social ties in employees' perceptions of organizational justice. Organization Science 14(6), 738-53

Uzzi, B. (1996). The sources and consequences of embeddedness for the economic performance of organizations: The network effect. American Sociological Review, 61, $674-$ 698.

van Dyke, N. \& McCammon, H. J. (2010). Strategic alliance: Coalition building and social movements. University of Minnesota Press

Vebrugge, L. M. (1979). Multiplexity in adult friendships. Social Forces, 57(4), 1286-309. 
Wang, D. J., \& Soule, S. A. (2012). Social movement organizational collaboration: Networks of learning and the diffusion of protest tactics, 1960-19951. American Journal of Sociology, 117(6), 1674-1722.

Wang, P., Robins, G., \& Pattison, P. (2008). PNet: Program for the simulation and estimation of P* Exponential Random Graph Models-User Manual. Retrieved from http://www.sna.unimelb.edu.au/pnet/pnet.html

Wellman, B. (1983). Network analysis: Some basic principles. Sociological Theory, 1, 155-200.

Weber, M. S. (2012). Newspapers and the Long-Term Implications of Hyperlinking. Journal of Computer-Mediated Communication, 17(2), 187-201.

White, H. C. (2008) Identity and control: A structural theory of social action. Princeton University Press.

Wheeldon, P. D. (1969). The operation of voluntary associations and personal networks in the political processes of an inter-ethnic community. In J. D. Mitchell (Ed.), Social networks in urban situations. Manchester University Press.

Young, L. E., \& Leonardi, P. M. (2012). Social issue emergence on the Web: A dual structurational model. Journal of Computer-Mediated Communication, 17(2), 231-246.

Zald, M. N. \& Ash, R. (1966). Social movement organizations: Growth, decay and change. Social Forces, 44(3), 327-341.

Zald, M. N. \& McCarthy, J. D. (1980). Social movement industries: Competition and cooperation among movement organizations. Research in Social Movements, Conflicts, and Change, 3, 1-20.

Zhao, Y. \& Rank, O. (2013). Interdependencies between working relations: Multivariate ERGMs for advice and satisfaction. In D. Lusher, J. Koskinen \& G. Robins (Eds.), Exponential Random Graph Models for social networks: Theory, methods, and applications. Cambridge University Press 